\title{
Fatty Acid $\beta$-Oxidation Plays a Key Role in Regulating cis-Palmitoleic Acid Levels in the Liver
}

\author{
Kohei Kawabata, ${ }^{a}$ Minako Karahashi, ${ }^{a}$ Takeshi Sakamoto, ${ }^{a}$ Yukiho Tsuji, ${ }^{a}$ Tohru Yamazaki, ${ }^{a}$ \\ Mari Okazaki, ${ }^{a}$ Atsushi Mitsumoto, ${ }^{b}$ Naomi Kudo, ${ }^{* a}$ and Yoichi Kawashima ${ }^{a}$ \\ ${ }^{a}$ School of Pharmaceutical Sciences, Josai University; 1-1 Keyakidai, Sakado, Saitama 350-0295, Japan: and \\ ${ }^{b}$ Faculty of Pharmaceutical Sciences, Josai International University; 1 Gumyo, Togane, Chiba 283-8555, Japan. \\ Received June 11, 2016; accepted August 29, 2016
}

\begin{abstract}
Different monounsaturated fatty acid (MUFA) species have distinct pathophysiological activities. cisPalmitoleic acid (16:1n-7) was previously reported to improve insulin sensitivity in animal studies. The proportions of hepatic MUFAs are generally considered to reflect changes in the activities of fatty acid modifications ( $\Delta 9$ desaturation and fatty acid elongation). However, hepatic levels of 16:1n-7 are markedly lower than those of oleic acid (18:1n-9). Nevertheless, no convincing explanation has yet been provided for the low level of 16:1n-7. We hypothesized that fatty acid degradation plays a key role in maintaining a low 16:1n-7 proportion in the liver. In order to corroborate the link between $\beta$-oxidation and the proportion of 16:1n-7, rats were fed a control diet, fed a fat-free diet to up-regulate fatty acid modifications, but not $\beta$-oxidation, or treated with clofibric acid to up-regulate fatty acid modifications and $\beta$-oxidation. The nutritional manipulation markedly increased the proportions of 16:1n-7, 18:1n-9, and cis-vaccenic acid (18:1n-7). Although the pharmacological manipulation enhanced fatty acid modifications to largely the same extent as the nutritional manipulation and markedly elevated the proportion of 18:1n-9, those of 16:1n-7 and 18:1n-7 remained largely unchanged. The oxidation rates of 16:1n-7, 18:1n-9, and 18:1n-7 in liver slices were in the following order: 16:1n-7 $>18: 1 \mathrm{n}-7 \doteqdot 18: 1 \mathrm{n}-9$ in control livers, and were increased by the pharmacological manipulation and decreased by the nutritional manipulation. These results strongly suggest that $\beta$-oxidation, in concert with fatty acid modifications, plays a key role in regulating the MUFA profile and is crucially involved in maintaining low 16:1n-7 levels in the liver.
\end{abstract}

Key words cis-palmitoleic acid; liver; fatty acid $\beta$-oxidation; monounsaturated fatty acid; $\Delta 9$ desaturation; fatty acid elongation

As components of complex lipids such as glycerolipids and cholesteryl esters (CE), fatty acids are fundamental constituents of membranes, energy stores, and mediators or signals that regulate cellular functions. In recent studies, attempts have been made to differentiate among particular fatty acid molecules according to their propensity to affect biological and physiological processes, such that specific fatty acid species are presently recognized to have distinct roles in cellular processes and influence a number of molecular pathways in tissues and organs. ${ }^{1-3)}$ Among fatty acid species, monounsaturated fatty acids (MUFAs) are fatty acids that are of particular interest in terms of their biological and pathophysiological significance. As features common to MUFAs, the relative abundance of MUFAs to saturated fatty acids in cells markedly affects cellular physiology, such as membrane fluidity, cell proliferation, lipid-mediated cytotoxicity, the pathogenesis of cancer, programmed cell death, and the unfolded protein response. $^{1-5)}$ The main MUFAs that reside in the tissues and organs of humans and rodents are oleic (18:1n-9), cis-palmitoleic (16:1n-7), and cis-vaccenic acids (18:1n-7). A growing body of evidence suggests that three MUFAs: 16:1n-7, 18:1n-7, and 18:1n-9, differ in terms of their biological significance. Regarding 16:1n-7, extensive studies over recent years have revealed the unique features of $16: 1 \mathrm{n}-7$ in terms of biological functions and health properties. ${ }^{6}{ }^{6}$ Cao et al. demonstrated that circulating 16:1n-7 levels positively correlated with insulin sensitivity in animal models. ${ }^{7}$ Subsequent studies performed on cultured cells, animals, and humans have suggested that 16:1n-7 enhances whole-body glucose disposal, suppresses hepatic steatosis, reduces stearoyl-CoA desaturase (SCD) 1, and modulates the metabolism of triacylglycerols (TAG) and glucose in white adipose tissue. ${ }^{6-9)}$ These findings generated expectations on the physiological significance of 16:1n-7 for metabolic homeostasis in humans. However, several lines of evidence from studies performed on human subjects have suggested contradictory outcomes; namely, circulating levels of $16: 1 n-7$ are not necessarily beneficial for human health. ${ }^{10-12)}$ As for 18:1n-7, a recent study suggested a role for $18: 1 n-7$ in the development of chronic kidney disease. ${ }^{13)}$ Another study indicated an inverse association between 18:1n-7 in red blood cells and the risk of myocardial infarction. ${ }^{12}$ Recent findings obtained using cultured cells and animals have further demonstrated the suppression of lipogenesis by 18:1n-7 and identified a link between 18:1n-7 synthesis and gluconeogenesis. ${ }^{14)}$ $18: 1 n-9$ produced in the liver has been suggested to regulate adipose tissue lipogenesis and fatty acid oxidation. ${ }^{15)}$ Thus, irrespective of whether their effects are beneficial or detrimental to human health, $16: 1 n-7,18: 1 n-7$, and $18: 1 n-9$ appear to be fatty acid species that are biologically active.

Fatty acid profiles in the tissues and organs of animals are considered to mainly reflect dietary fatty acid intake, the endogenous conversion of ingested fatty acids by fatty acid modifications (desaturation and elongation), and the de novo synthesis of fatty acids. 18:1n-9 is the most abundant MUFA in dietary oils, and is, thus, readily available; however, 16:1n-7 and 18:1n-7 levels are low in common dietary oils. Since it is 
conceivable that the liver is the principal site for the synthesis of these three MUFAs, and also that the liver widely distributes MUFAs to extra-hepatic tissues through the circulation, it is important to understand how MUFA proportions are regulated in the liver. Regarding the de novo synthesis of MUFAs in the liver, palmitic acid (16:0) is generated de novo by the action of fatty acid synthase (FAS). 16:0 then enters the fatty acid modification process after being activated to palmitoylCoA, a process that involves $\Delta 9$ desaturation, which mediates the addition of a cis double bond to saturated fatty acids, and fatty acid elongation, which adds a C2 unit to produce chainelongated fatty acids. Palmitoyl-CoA is initially elongated by palmitoyl-CoA chain elongation (PCE) to stearoyl-CoA, which is subsequently desaturated by $\Delta 9$ desaturation to yield oleoyl-CoA. Palmitoyl-CoA is initially desaturated by $\Delta 9$ desaturation to produce cis-palmitoleoyl-CoA, after which the cis-palmitoleoyl-CoA chain elongation (POCE) ensues, resulting in the formation of cis-vaccenoyl-CoA. Therefore, the MUFA profile in the liver may be regulated by $\Delta 9$ desaturation and fatty acid chain elongation. ${ }^{16,17)}$ Moreover, previous studies have demonstrated that $\Delta 9$ desaturase, which is known to be SCD, catalyzes the desaturation of stearoyl-CoA and palmitoyl-CoA at largely the same rate in the livers of rats. ${ }^{18-20)}$ Collectively, these findings imply that the abundance of $16: 1 n-7$ plus $18: 1 n-7$ is similar to that of $18: 1 n-9$ in the liver. Nevertheless, the proportions of MUFAs, in particular 16:1n-7, are known to markedly fluctuate in the liver in response to changes in pathophysiological and nutritional conditions. ${ }^{17,21,22)}$ However, difficulties are associated with explaining these alterations based on changes in the activities of desaturation and elongation alone. Our previous studies clearly showed that the treatment of rats with 2-(4-chlorophenoxy)-2-methylpropionic acid (clofibric acid) induced SCD and increased the hepatic content and proportion of $18: 1 n-9$, whereas those of $16: 1 n-7$ and 18:1n-7 were markedly lower. ${ }^{23)}$ This apparent discordance between previous studies ${ }^{18-20)}$ and our findings ${ }^{23)}$ strongly suggests the existence of additional player(s) in the regulation of the MUFA profile in the liver, a factor that is indispensable for elucidating the low proportion of 16:1n-7 in the livers of rats. In an attempt to resolve this issue, on the basis of the concept that the abundance of an endogenous product results from an appropriate balance between its formation and degradation, we speculated that fatty acid oxidation is positively related to the regulation of the characteristic profile of MUFAs in the liver. However, research focusing on the link between the MUFA profile and fatty acid oxidation in the liver is limited. ${ }^{24}$

Therefore, we hypothesized that fatty acid oxidation may be involved in regulating the proportion of MUFA, particularly $16: 1 n-7$, in the liver. In order to test this hypothesis, rats were fed a control diet, fed a fat-free diet to up-regulate fatty acid modifications (SCD, PCE, and POCE), but not $\beta$-oxidation, or treated with clofibric acid to up-regulate both fatty acid modifications and $\beta$-oxidation. We estimated the relationships between the activities of fatty acid modifications, the activities of $\beta$-oxidation, and the proportions of $16: 1 \mathrm{n}-7,18: 1 \mathrm{n}-7$, and 18:1n-9 in the lipid classes in the liver. The results obtained strongly suggest that $\beta$-oxidation, in concert with desaturation and fatty acid elongation, plays a key role in maintaining low 16:1n-7 levels in the liver.

\section{MATERIALS AND METHODS}

Materials The following materials were obtained from the indicated commercial sources: an anti-adipose triglyceride lipase (ATGL) mouse monoclonal antibody (mAb) (sc 365278) and goat anti rabbit immunoglobulin $\mathrm{G}$ ( $\mathrm{IgG}$ ) horseradish peroxidase-conjugated secondary antibody (Ab) (sc 2004) (Santa Cruz Biotechnology Inc., Dallas, TX, U.S.A.); an anti-acetylCoA carboxylase (ACC) rabbit mAb (ab 45174), anti-carnitine palmitoyltransferase 1a (CPT1a) mouse mAb (ab 128568), antiFAS rabbit $\mathrm{mAb}$ (ERP 7465), and anti- $\beta$-actin mouse $\mathrm{mAb}$ (ab 6276) (Abcam, Cambridge, U.K.); and a horse anti-mouse IgG horseradish peroxidase-conjugated secondary Ab (\#7076) (Cell Signaling Technology, Danvers, MA, U.S.A.). cis-Vaccenoyl-CoA was prepared according to the method reported previously ${ }^{25)}$ using cis-vaccenoyl chloride (Nu-Chek Prep Inc., Elysian, MN, U.S.A.) and CoA (Oriental Yeast Co., Tokyo, Japan). $\left[1-{ }^{14} \mathrm{C}\right] 18: 1 \mathrm{n}-7$ was prepared by the method reported previously. ${ }^{26)}$ In brief, in order to prepare $\left[1-{ }^{14} \mathrm{C}\right] 18: 1 \mathrm{n}-7$ ([1$\left.{ }^{14} \mathrm{C}\right]$ (11Z)-octadec-11-enoic acid), (10Z)-heptadec-10-en-1-ol (Funakoshi Co., Ltd., Tokyo, Japan) was converted to the corresponding iodide ((7Z)-17-iodoheptadec-7-ene) via a mesylate. The iodide was then extended with $\mathrm{K}^{14} \mathrm{CN}$ (American Radiolabeled Chemicals, Inc., St. Louis, MO, U.S.A.), and hydrolysis of the resulting nitrile yielded the desired $\left[1-{ }^{14} \mathrm{C}\right] 18: 1 \mathrm{n}-7$.

Animals and Experimental Design All animal procedures were approved by Josai University's Institutional Animal Care Committee in accordance with the Guidelines for the Proper Conduct of Animal Experiments (Science Council of Japan). Five-week-old male Wistar rats were obtained from SLC (Hamamatsu, Japan). Animals were fed a standard diet (CE-2; Clea Japan Inc., Tokyo, Japan) ad libitum and allowed free access to water. After acclimatization for 1 week, rats were divided into three groups. Group 1 was fed a standard diet (CE-2) for $28 \mathrm{~d}$. The fatty acid composition (by mol\%) of the standard diet (CE-2) was as follows: 16:0, 23.2\%; 16:1n-7, $2.0 \% ; 18: 0,2.4 \% ; 18: 1 n-9,19.7 \% ; 18: 1 n-7,2.2 \%$; linoleic acid (18:2n-6), 42.1\%; $\alpha$-linolenic acid (18:3n-3), 3.6\%; arachidonic acid (20:4n-6), 0.2\%; 5,8,11,14,17-eicosapentaenoic acid (20:5n-3), 2.9\%; 7,10,13,16,19-docosapentaenoic acid (22:5n-3), $0.3 \%$; and 4,7,10,13,16,19-docosahexaenoic acid (22:6n-3), $1.3 \%$. Group 2 was fed a fat-free diet for $28 \mathrm{~d}$. The fat-free diet (fat-deprived AIN93G) was purchased from Oriental Yeast Co. and contained (by weight): $46.75 \%$ corn starch, $13.2 \%$ $\alpha$-starch, $10 \%$ sucrose, $5 \%$ cellulose, $20 \%$ casein, $1 \%$ vitamin mix (AIN93), 3.5\% mineral mix (AIN93G), 0.30\% L-cysteine, and $0.25 \%$ choline bitartrate. Group 3 was fed a diet $(\mathrm{CE}-2)$ admixed with $0.5 \%(\mathrm{w} / \mathrm{w})$ clofibric acid (Sigma-Aldrich Inc., St. Louis, MO, U.S.A.) for $7 \mathrm{~d}$ before being sacrificed. At the age of 10 weeks, rats were sacrificed in the fed state. Rats were anesthetized with diethyl ether, and blood was withdrawn from the inferior vena cava. The liver was rapidly removed, washed with ice-cold saline, and weighed. One part of the liver was frozen in liquid nitrogen and stored at $-80^{\circ} \mathrm{C}$ until the analysis of mRNA. The rest of the liver was used for lipid analyses, the preparation of homogenates, microsomes, the cytosol, and the cytoplasmic fraction, and the preparation of liver slices. The parts of the liver that were used to prepare homogenates, microsomes, and the cytosol were perfused with ice-cold saline. Protein concentrations in these preparations were measured by the method of Lowry et al. ${ }^{27)}$ using bovine 
serum albumin (BSA) (Sigma-Aldrich) as a standard.

Lipid Analysis After the addition of known amounts of cholesteryl heptadecanoate and triheptadecanoin as internal standards, total lipids were extracted from a piece of the liver using the method of Bligh and Dyer. ${ }^{28)}$ After the addition of a known amount of nonadecanoic acid as an internal standard, one portion of the extracted lipids was saponified with $10 \%$ methanolic $\mathrm{KOH}$ at $80^{\circ} \mathrm{C}$ for $60 \mathrm{~min}$ under a nitrogen atmosphere. After the removal of unsaponifiable matter with $n$-hexane three times, samples were acidified with $6 \mathrm{M} \mathrm{HCl}$ and unesterified fatty acids were extracted with $n$-hexane three times. Another portion of the total lipid extract was used to elucidate the acyl composition of lipid classes. CE, TAG, diacylglycerols (DAG), and phospholipids were separated by TLC on silica gel $G$ plates, which were developed with $n$ hexane-diethyl ether-acetic acid $(80: 30: 1$, v/v/v). After visualization by spraying $0.001 \%(\mathrm{w} / \mathrm{v})$ primuline in $80 \%$ acetone, the regions on each plate that corresponded to specific classes of lipids were scraped off and transferred to tubes. Known amounts of methyl heptadecanoate were added to the tubes containing phospholipids or DAG as an internal standard. Lipids were extracted from silica gel as described previously. ${ }^{29}$ ) Methyl esters of fatty acids were prepared from each extract using sodium methoxide/methanol for TAG and phospholipids, and $\mathrm{HCl} /$ methanol for DAG. $\mathrm{CE}$, which was extracted from silica gel, was saponified once, and the fatty acids released were then extracted separately from cholesterol and converted into methyl esters using $\mathrm{HCl} /$ methanol. The composition of fatty acid methyl esters was measured by GLC (Shimadzu GC-2014; Shimadzu, Kyoto, Japan), equipped with a flameionization detector using a fused silica capillary column (SLB-IL100, $30 \mathrm{~m} \times 0.32 \mathrm{~mm}$ internal diameter, film thickness $0.26 \mu \mathrm{m}$ ) (Sigma-Aldrich) with helium gas as a carrier gas, as described previously. ${ }^{30)}$

Quantitative Real-Time PCR Total RNA was isolated from liver tissues using the QIAzol reagent and RNeasy kit (QIAGEN, Hilden, Germany). cDNA was synthesized from $500 \mathrm{ng}$ of total RNA with avian myeloblastosis virus reverse transcriptase (TaKaRa Bio Inc., Shiga, Japan). PCR amplification was conducted using SYBR Premix EX Taq (TaKaRa). Amplification and detection were performed with the Step One Plus real-time PCR system (Life Technologies Corp., Carlsbad, CA, U.S.A.). The thermal cycling program was as follows: 10 -s denaturation steps at $95^{\circ} \mathrm{C}$, followed by 50 cycles of 5-s denaturation steps at $95^{\circ} \mathrm{C}$, and 34 -s annealing steps at $60^{\circ} \mathrm{C}$. After the reaction, dissociation curve analyses were performed in order to confirm the amplification of a single PCR product. Changes in gene expression were calculated by using the comparative threshold cycle $(C \mathrm{t})$ method. $C \mathrm{t}$ values were first normalized by subtracting the $C \mathrm{t}$ value obtained from $\beta$-actin (control). The sequences of primers used in this study are listed in Supplementary Table 1.

Western Blot Analysis Tissue lysates were prepared as described previously. ${ }^{31)}$ In brief, one portion of the liver was homogenized in lysis buffer $(25 \mathrm{~mm}$ Tris- $\mathrm{HCl}[\mathrm{pH}$ 7.6], $150 \mathrm{~mm} \mathrm{NaCl}, 1 \% \mathrm{NP} 40,1 \%$ sodium deoxycholate, and $0.1 \%$ sodium dodecyl sulfate (SDS) supplemented with protein inhibitors [aprotinin at $2 \mu \mathrm{g} / \mathrm{mL}$, bestatin at $13.8 \mu \mathrm{g} /$ $\mathrm{mL}$, leupeptin at $10 \mu \mathrm{g} / \mathrm{mL}$, pepstatin at $5 \mu \mathrm{g} / \mathrm{mL}$, and 4-(2-aminoethyl)-benzenesulfonyl fluoride hydrochloride at $250 \mu \mathrm{g} / \mathrm{mL}]$ ) using a Polytrone homogenizer (Kinematica,
Luzern, Switzerland) at $4^{\circ} \mathrm{C}$, incubated on ice for $30 \mathrm{~min}$, and centrifuged at $10000 \times \boldsymbol{g}$ for $10 \mathrm{~min}$. The supernatants were recentrifuged at $10000 \times \mathbf{g}$ for $10 \mathrm{~min}$, and the resulting supernatants were collected in order to measure protein concentrations using the BCA protein assay reagent (Thermo Fisher Scientific, Waltham, MA, U.S.A.). A Western blot analysis of FAS, ACC, ATGL, and CPT1a was performed using the tissue lysate as described previously. ${ }^{31,32)}$ Proteins (15 $\mu \mathrm{g}$ each) were separated by SDS-polyacrylamide gel electrophoresis on $10 \%$ (ATGL and CPT1a) or $7.5 \%$ (ACC and FAS) gels. Proteins were transferred to polyvinylidene difluoride membranes, incubated with the primary $\mathrm{Ab}$ at room temperature for $1 \mathrm{~h}$ (FAS $(1: 1000)$, ACC $(1: 2000)$, CPT1a $(1: 1000)$, and $\beta$-actin $(1: 5000))$ or $2 \mathrm{~h}$ (ATGL $(1: 600))$ after the incubation at $4^{\circ} \mathrm{C}$ overnight with blocking buffer (Tris-buffered saline containing $0.1 \%$ Tween 20,5\% skim milk, and 1\% BSA), and this was followed by an incubation with the secondary $\mathrm{Ab}$ at room temperature for $1 \mathrm{~h}$ (FAS, ACC, CPTla, and $\beta$-actin) or $2 \mathrm{~h}$ (ATGL). They were then visualized using the ECL Prime Western blotting Detection Reagent (GE Healthcare Japan, Tokyo, Japan), and quantitation of the amounts of the proteins was performed using a luminoimage analyzer (ChemiDoc $^{\mathrm{TM}}$ XRS Plus; Bio-Rad Laboratories, Hercules, CA, U.S.A.) and normalized by loaded $\beta$-actin.

\section{Assays for FAS, SCD, PCE, POCE, and ATGL}

\section{Assays for FAS}

FAS activities were measured using the hepatic cytosol as an enzyme source. One portion of perfused livers was homogenized in 1.5 volumes of phosphate-bicarbonate buffer $(70 \mathrm{mM}$ $\mathrm{KHCO}_{3}, 85 \mathrm{~mm} \mathrm{~K} \mathrm{~K}_{2} \mathrm{HPO}_{4}, 9 \mathrm{~mm} \mathrm{K \textrm {K } _ { 2 }} \mathrm{PO}_{4}$, and $1 \mathrm{~mm}$ dithiothreitol) $(\mathrm{pH} 8.0)$ in a Potter glass-Teflon homogenizer. The homogenates were centrifuged at $20000 \times \boldsymbol{g}$ for $10 \mathrm{~min}$. The supernatant obtained was centrifuged at $105000 \times \boldsymbol{g}$ for $60 \mathrm{~min}$, and the resulting supernatant was stored at $-80^{\circ} \mathrm{C}$ until used. All operations were performed at $0-4^{\circ} \mathrm{C}$. FAS activity was measured spectrophotometrically according to a previously reported method. ${ }^{33)}$ In brief, the assay mixture contained $33 \mu \mathrm{M}$ acetyl-CoA (Sigma-Aldrich), $100 \mu \mathrm{M}$ malonyl-CoA (SigmaAldrich), $100 \mu \mathrm{M}$ reduced nicotinamide adenine dinucleotide phosphate (NADPH) (Oriental Yeast Co.), $1 \mathrm{~mm}$ ethylenediaminetetraacetic acid (EDTA), $1 \mathrm{~mm}$ 2-mercaptoethanol, $50 \mu \mathrm{g}$ cytosolic protein, and $100 \mathrm{~mm}$ phosphate buffer $(\mathrm{pH} 7.0)$ in a total volume of $1 \mathrm{~mL}$. The oxidation of NADPH was followed at $340 \mathrm{~nm}$ at $30^{\circ} \mathrm{C}$. The initial slope was used to calculate the rate of fatty acid synthesis. A correction was made for the rate of NADPH oxidation in the absence of malonyl-CoA.

Assay for SCD, PCE, and POCE

The activities of SCD, PCE, and POCE were measured using hepatic microsomes as an enzyme source. Hepatic microsomes were prepared by sequential centrifugation as previously described. ${ }^{29)}$ SCD activities were measured spectrophotometrically as reported previously ${ }^{29}$ and activity was presented as the rate constant $\left(k^{+}\right)$for the stearoyl-CoAstimulated re-oxidation of reduced nicotinamide adenine dinucleotide (NADH)-reduced cytochrome $b_{5}$. The activities of PCE and POCE were assayed as the rate of conversion of palmitoyl-CoA (Sigma-Aldrich) to $\left[{ }^{14} \mathrm{C}\right] 18: 0$ and that of cis-palmitoleoyl-CoA (Sigma-Aldrich) to $\left[{ }^{14} \mathrm{C}\right] 18: 1 \mathrm{n}-7$, respectively, by estimating the incorporation of the $\mathrm{C} 2$ unit from $\left[2-{ }^{14} \mathrm{C}\right]$ malonyl-CoA (American Radiolabeled Chemicals), according to a previously reported method. ${ }^{17,34)}$ 
Assay for ATGL

TAG hydrolase activity was measured as previously described $^{35)}$ with some modifications. ${ }^{31)}$ A cytoplasmic fraction was prepared from the liver as reported previously. ${ }^{31)}$ Triolein [carboxy $-{ }^{14} \mathrm{C}$ ] (PerkinElmer, Inc., Waltham, MA, U.S.A.) was purified before use by TLC on silica gel G plates, which were developed with $n$-hexane-diethyl ether-acetic acid $(80: 30: 1, \mathrm{v} / \mathrm{v} / \mathrm{v})$. A substrate, $\left[{ }^{14} \mathrm{C}\right]$ triolein $(33.3 \mathrm{GBq} / \mathrm{mol})$ mixed with phosphatidylcholine-phosphatidylinositol $(3: 1)$, was prepared as described previously. ${ }^{31)}$ Substrate solution with the cytoplasmic fraction and buffer $(20 \mathrm{~mm}$ potassium phosphate [pH 7.0], $1 \mathrm{~mm}$ EDTA, $1 \mathrm{~mm}$ dithioerythritol, and $0.02 \%(\mathrm{w} / \mathrm{v})$ defatted BSA) were incubated at $37^{\circ} \mathrm{C}$ for $60 \mathrm{~min}$. The control value, which was obtained from the incubation without the cytoplasmic fraction, was subtracted to give net TAG hydrolyzed by the cytoplasmic fraction.

In Vitro Mitochondrial and Peroxisomal Fatty Acid Oxidation in Liver Homogenates

Mitochondrial Fatty Acid Oxidation

Mitochondrial fatty acid oxidation was measured using a previously reported method. ${ }^{36)}$ In this assay, the rates of mitochondrial fatty acid oxidation were measured in liver homogenates, rather than in purified mitochondrial fractions in order to avoid possible damage to the organelles during centrifugation. Liver homogenates $(5 \%, \mathrm{w} / \mathrm{v})$ in $0.25 \mathrm{~m}$ sucrose containing $0.1 \%$ ethanol were prepared in a Dounce homogenizer with six strokes each of a loose and tight-fitting plunger. Modified Krebs-Henseleit bicarbonate buffer ( $\mathrm{pH}$ 7.4) containing no calcium, $2.4 \mathrm{~mm} \mathrm{MgSO}_{4}, 4.74 \mathrm{~mm} \mathrm{NaCl}, 118.46 \mathrm{~mm}$ $\mathrm{KCl}, 1.2 \mathrm{mM} \mathrm{KH}_{2} \mathrm{PO}_{4}$, and $25 \mathrm{~mm} \mathrm{NaHCO}$ was used as an incubation buffer. The radio-labeled fatty acids, $\left[1-{ }^{14} \mathrm{C}\right] 16: 1 \mathrm{n}-7$ (American Radiolabeled Chemicals), $\left[1-{ }^{14} \mathrm{C}\right] 18: 1 n-9$ (American Radiolabeled Chemicals), and $\left[1-{ }^{14} \mathrm{C}\right] 18: 1 \mathrm{n}-7$ (prepared as described in Materials and Methods), were purified just before use by TLC on silica gel $\mathrm{G}$ plates, which were developed with $n$-hexane-diethyl ether-acetic acid $(80: 30: 1, \mathrm{v} / \mathrm{v} / \mathrm{v})$. Two milliliters of the mixture contained $0.2 \mathrm{~mm}$ sodium $\left[1-{ }^{14} \mathrm{C}\right]-$ labeled fatty acid (one each of 16:1n-7, 18:1n-7, and 18:1n-9) (specific radioactivity, $27.75 \mathrm{GBq} / \mathrm{mol}$ ), bound to $7.2 \mathrm{mg} / \mathrm{mL}$ of defatted BSA (molar ratio of substrate : albumin=1.67); $4 \mathrm{~mm}$ ATP (Oriental Yeast Co.); $0.5 \mathrm{~mm}$ L-carnitine (Oriental Yeast Co.); $0.05 \mathrm{~mm} \mathrm{CoA}$; and $2 \mathrm{~mm}$ dithiothreitol. A total of $0.5 \mathrm{~mL}$ of the $5 \%(\mathrm{w} / \mathrm{v})$ liver homogenate in sucrose/ethanol was added to the mixture. Fatty acid oxidation was measured in the presence and absence of $2 \mathrm{~mm} \mathrm{KCN}$, and the cyanide-sensitive part of oxidation was taken as mitochondrial oxidation. Incubations were performed in scintillation vials that initially contained the buffer, $\left[1-{ }^{14} \mathrm{C}\right]$-labeled fatty acid, and the appropriate components listed above. The vials were gassed with $\mathrm{O}_{2}-\mathrm{CO}_{2}(95: 5, \mathrm{v} / \mathrm{v})$, capped with rubber stoppers from which plastic center-wells were suspended, and shaken (90 oscillations $/ \mathrm{min}$ ) at $37^{\circ} \mathrm{C}$. The incubation was started with the addition of homogenates, and the vials were incubated at $37^{\circ} \mathrm{C}$ for $3 \mathrm{~min}$ with shaking. The incubation was terminated by injecting $1 \mathrm{~mL}$ of $0.6 \mathrm{M} \mathrm{HClO}_{4}$ into the vial, and $0.2 \mathrm{~mL}$ of $1 \mathrm{M}$ benzethonium hydroxide in methanol was injected into the center well. The incubation vials were shaken at room temperature for another $45 \mathrm{~min}$ in order to trap radio-labeled $\mathrm{CO}_{2}$ in benzethonium hydroxide/methanol. The contents of the center well were transferred to a counting vial and mixed with scintillation fluid. Radioactivity was measured using a liquid scintillation counter. The acidified content of the vial was transferred to a tube; after centrifugation $(1500 \times \boldsymbol{g}$ at room temperature for $10 \mathrm{~min}$ ), the supernatant was transferred to a tube and neutralized with $5 \mathrm{M} \mathrm{KOH}$. After the addition of $0.7 \mathrm{~mL}$ of $3 \mathrm{M}$ acetate buffer ( $\mathrm{pH} 4.0$ ), the reaction mixture was extracted four times with petroleum ether in order to remove traces of the radio-labeled fatty acid. An aliquot of the aqueous phase was mixed with scintillation fluid, and radioactivity was counted (acid-soluble oxidation products). The value that was obtained from the incubation in the presence of $\mathrm{KCN}$ (corresponding to peroxisomal $\beta$-oxidation) was subtracted to give the mitochondrial $\beta$-oxidation rate. The rate of fatty acid oxidation is presented as the sum of acid-soluble oxidation products and $\mathrm{CO}_{2}$.

\section{Peroxisomal Fatty Acid Oxidation}

In order to assay peroxisomal $\beta$-oxidation, one portion of the liver was homogenized with 4 volumes of $0.25 \mathrm{M}$ sucrose-1 mM EDTA-10 mM Tris- $\mathrm{HCl}$ (pH 7.4) in a Potter glassTeflon homogenizer. Peroxisomal $\beta$-oxidation was assayed by the method of Lazarow and de Duve. ${ }^{37)}$ Acyl-CoA-dependent reduction of oxidized form of nicotinamide adenine dinucleotide $\left(\mathrm{NAD}^{+}\right)$was followed spectrophotometrically at $340 \mathrm{~nm}$.

Ex Vivo Fatty Acid Oxidation in Liver Slices Rats were killed and their livers were quickly removed. The left lobe was separated, and precision-cut liver slices $(8 \mathrm{~mm}$ in diameter, with a thickness of $400 \mu \mathrm{m}$ and weight of $0.18 \mathrm{~g}$ ) were prepared using a Krumdieck tissue slicer (Alabama Research Development, Munford, AL, U.S.A.) as reported previously. ${ }^{38)}$ The oxidation rates of $16: 1 n-7,18: 1 n-7$, and $18: 1 n-9$ were assessed as reported previously. ${ }^{39)}$ Radio-labeled fatty acids were purified just before use by TLC on silica gel G plates, which were developed with $n$-hexane-diethyl ether-acetic acid $(80: 30: 1, \mathrm{v} / \mathrm{v} / \mathrm{v})$. In brief, two liver slices $(0.36 \mathrm{~g})$ were incubated in a glass vial that contained $2 \mathrm{~mL}$ of Krebs-Henseleit buffer ( $\mathrm{pH} 7.4$ ) comprising $5 \mathrm{~mm}$ glucose, $0.25 \mathrm{~mm}\left[1-{ }^{14} \mathrm{C}\right]-$ labeled fatty acid (one each of 16:1n-7, 18:1n-7, and 18:1n-9) (specific radioactivity, $185 \mathrm{GBq} / \mathrm{mol}$ ), and $0.6 \% \mathrm{BSA}$ (essentially fatty acid-free) at $37^{\circ} \mathrm{C}$ for $30 \mathrm{~min}$ under an $\mathrm{O}_{2}-\mathrm{CO}_{2}$ atmosphere (95:5, v/v) with shaking (90 oscillations/min). The vials were capped with rubber stoppers from which plastic center-wells were suspended. The incubation was terminated by the injection of $1 \mathrm{~mL}$ of $0.6 \mathrm{M} \mathrm{HClO}_{4}$ into the vial, and $0.2 \mathrm{~mL}$ of $1 \mathrm{M}$ benzethonium hydroxide in methanol was injected into the center well. The vials were shaken (60 oscillations/ $\mathrm{min}$ ) at room temperature for $45 \mathrm{~min}$ in order to trap radiolabeled $\mathrm{CO}_{2}$ into benzethonium hydroxide. The contents of the center well were transferred to a counting vial and mixed with scintillation fluid, and radioactivity was measured using a liquid scintillation counter. The liver slice was homogenized with the incubation mixture that had been acidified with $\mathrm{HClO}_{4}$. After being centrifuged at $1500 \times \boldsymbol{g}$ for $10 \mathrm{~min}$, the resulting supernatant was neutralized with $5 \mathrm{~m} \mathrm{KOH}$, and its $\mathrm{pH}$ was then adjusted to 4 using $0.7 \mathrm{~mL}$ of $3 \mathrm{M}$ acetate buffer ( $\mathrm{pH} 4.0$ ); the aqueous phase obtained was extracted five times with petroleum ether to remove traces of the $\left[{ }^{14} \mathrm{C}\right]$-labeled fatty acid. An aliquot of the aqueous phase was mixed with scintillation fluid, and radioactivity was evaluated as acid-soluble oxidation products using a liquid scintillation counter. The rate of fatty acid oxidation is presented as the sum of acid-soluble oxidation products and $\mathrm{CO}_{2}$ per $\mathrm{g}$ liver slice.

Statistical Analysis Data are shown as the mean \pm standard 


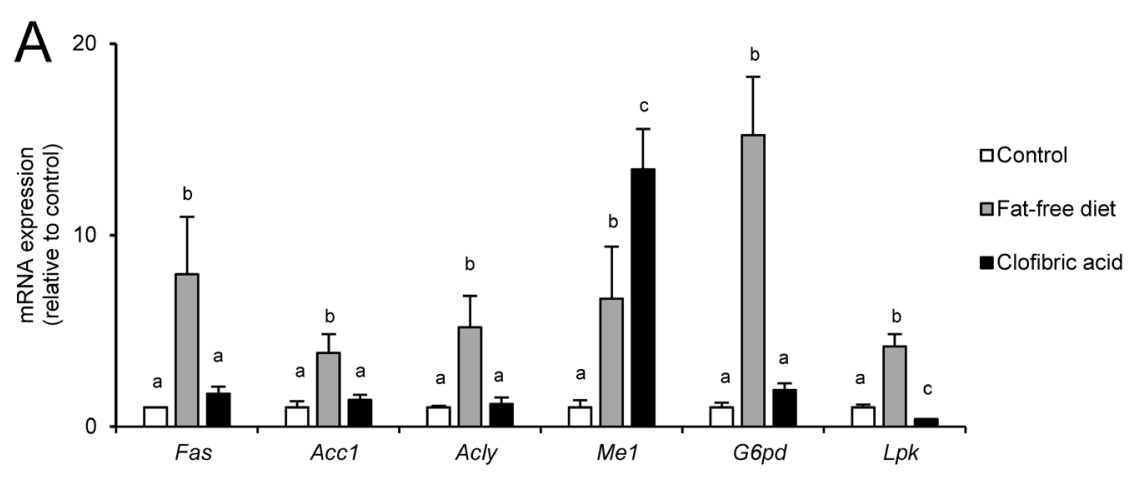

B

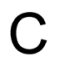

$\mathrm{D}$
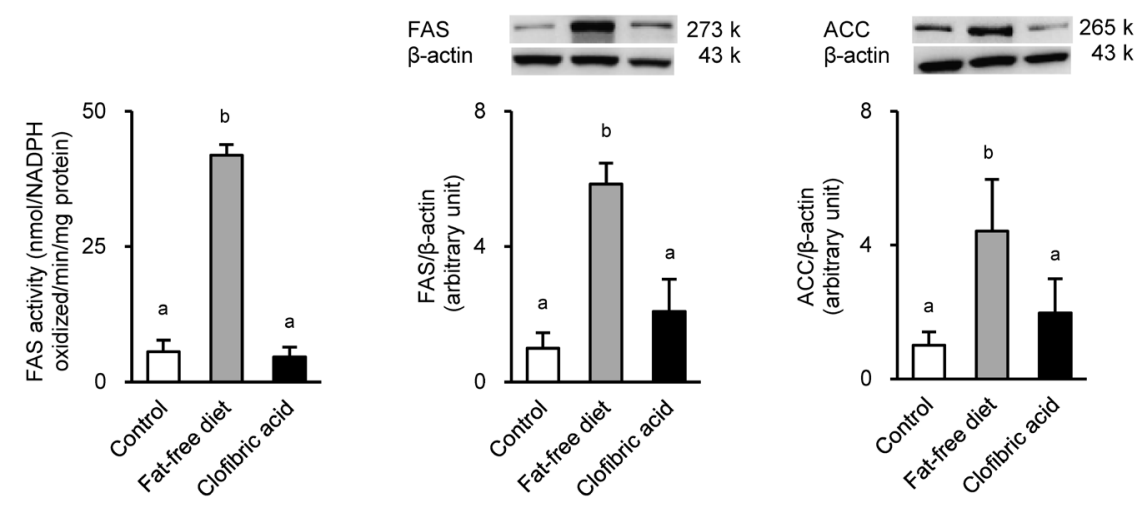

$E$

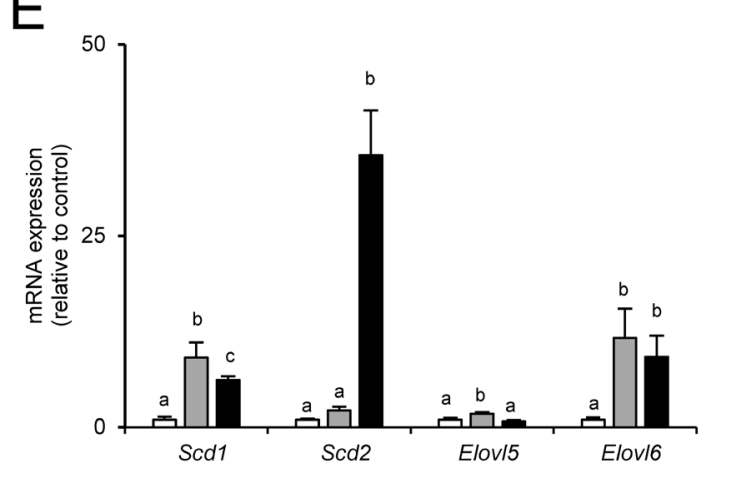

aControl

口Fat-free diet

-Clofibric acid

F

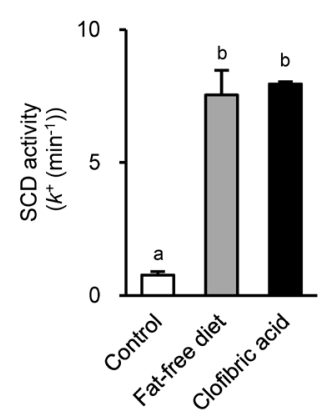

G

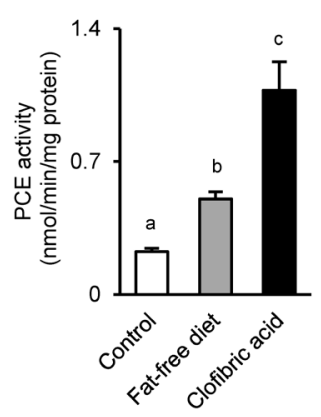

$\mathrm{H}$

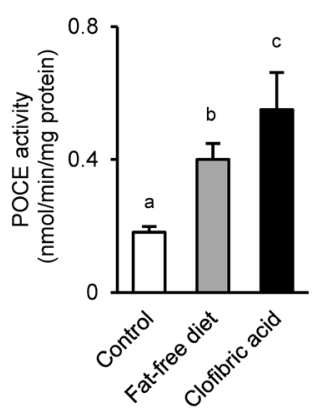

Fig. 1. mRNA, Activity, and Protein Levels of Enzymes Related to De Novo Fatty Acid Synthesis and MUFA Synthesis in the Liver

Rats were fed a standard diet for $28 \mathrm{~d}$, a fat-free diet for $28 \mathrm{~d}$, or a diet admixed with clofibric acid at $0.5 \%$ (w/w) for $7 \mathrm{~d}$. (A) mRNAs encoding FAS, ACC1, ACYL, ME1, $\mathrm{G} 6 \mathrm{PD}$, and LPK. (B) FAS activity in the hepatic cytosol. (C) FAS protein in the liver; visible bands represent FAS and $\beta$-actin as indicated. (D) ACC protein in the liver; visible bands represent ACC and $\beta$-actin as indicated. Regarding (C) and (D), immunoblotting was performed on liver extracts (15 $\mu \mathrm{g}$ of protein each). (E) mRNA encoding SCD1, SCD2, ELOVL5, and ELOVL6. (F) SCD activity in hepatic microsomes. (G) PCE activity in hepatic microsomes. (H) POCE activity in hepatic microsomes. Values represent the mean \pm S.D. $(n=5-6)$. ${ }^{\mathrm{a}, \mathrm{b}, \mathrm{c}}$ Means without a common superscript are significantly different $(p<0.05)$. 
deviation (S.D.). The homogeneity of variance was established using a one-way ANOVA. When a difference was significant $(p<0.05)$, Scheffé's multiple range test was used as a post-hoc test. Levels of significance were set at $p<0.05$.

\section{RESULTS}

Negligible Difference in the Up-Regulation of Desaturase and Fatty Acid Elongases in the Liver between FatFree Diet-Fed Rats and Clofibric Acid-Treated Rats In order to gain an insight into the molecular basis for changes in the MUFA proportion in the livers of fat-free diet-fed rats and clofibric acid-treated rats, the mRNA levels of key enzymes related to de novo fatty acid synthesis were measured (Fig. 1A). The levels of mRNAs encoding FAS, ACC1, ATP-citrate lyase (ACLY), malic enzyme 1 (ME1), glucose-6-phosphate dehydrogenase (G6PD), and L-type pyruvate kinase (LPK) were markedly increased in the livers of fat-free diet-fed rats. On the other hand, the treatment of rats with clofibric acid did not affect the expression of Fas, Accl, Acly, or G6pd; this pharmacological manipulation significantly augmented the mRNA level of $\mathrm{Mel}$ and conversely reduced that of Lpk (Fig. 1A). Fat-free diet feeding elevated the activity of FAS and protein levels of FAS and ACC over those in control rats, whereas the clofibric acid treatment did not change these variables (Figs. 1B-D). The expression of genes encoding the desaturases and elongases responsible for the synthesis of MUFAs was estimated (Fig. 1E). The mRNA levels of SCD1 were higher in both fat-free diet-fed and clofibric acid-treated rats than in control rats. Similarly, the mRNA levels of SCD2 were higher in fat-free diet-fed and clofibric acid-treated rats than in control rats. The mRNA levels of fatty acid elongase (ELOVL) 6 were markedly higher in fat-free diet-fed and clofibric acid-treated rats than in control rats. Feeding a fat-free diet increased the mRNA level of ELOVL5 by 1.75 -fold, but it was not significantly altered by the treatment with clofibric acid. In order to corroborate the functional significance observed in the expression of genes encoding desaturase and elongases for the synthesis of MUFAs, the activities of SCD, PCE, and POCE in hepatic microsomes were estimated (Figs. $1 \mathrm{~F}-\mathrm{H})$. SCD activity was markedly augmented in fat-free dietfed and clofibric acid-treated rats; the extent of the increase in its activity by the pharmacological manipulation was largely the same as that by the nutritional manipulation (Fig. 1F). The activities of PCE, which is proceeded by ELOVL6, ${ }^{40)}$ in the livers of fat-free diet-fed and clofibric acid-treated rats were 2.23- and 4.76-fold higher, respectively, than those in control rats (Fig. 1G). The activities of POCE, which is proceeded by ELOVL5 and ELOVL6, ${ }^{40)}$ were also higher in fat-free diet-fed (2.22-fold) and clofibric acid-treated rats (3.04-fold) than in control rats (Fig. 1H).

Marked Difference in the Hepatic MUFA Profile between Fat-Free Diet-Fed Rats and Clofibric Acid-Treated Rats Regarding MUFAs, the proportions (by $\mathrm{mol} \%$ ) of $16: 1 n-7,18: 1 n-7$, and $18: 1 n-9$ in total fatty acids in the livers of control rats were $1.84,4.01$, and $10.35 \%$, respectively (Table 1). The proportions of $16: 1 \mathrm{n}-7,18: 1 \mathrm{n}-7$, and $18: 1 \mathrm{n}-9$ within MUFAs in the livers of control rats were 11.2, 24.9, and $63.9 \%$, respectively (Fig. 2A). The proportions of the three MUFAs in total fatty acids in the liver were significantly increased by feeding rats a fat-free diet. Increases in the masses of $16: 1 \mathrm{n}-7,18: 1 \mathrm{n}-7$, and $18: 1 \mathrm{n}-9$ by fat-free diet feeding were 9.25-fold, 1.88-fold, and 2.90-fold greater, respectively, than control levels (Table 1, Fig. 2B); the proportions of 16:1n-7, 18:1n-7, and 18:1n-9 within MUFAs were 31.6, 14.0, and $54.4 \%$, respectively (Fig. $2 \mathrm{~A}$ ). In the livers of clofibric acidtreated rats, the proportion in total fatty acids and mass of $18: 1 n-9$ were 1.59- and 1.47-fold higher, respectively, than those in control rats (Table 1, Fig. 2B). In contrast to fat-free diet feeding, the treatment of rats with clofibric acid did not significantly change the proportion or mass of 16:1n-7 (Table 1, Fig. 2B). Moreover, the proportion and mass of 18:1n-7 were significantly lower in clofibric acid-treated rats than in control rats (Table 1, Fig. 2B). As a result, the proportions of 16:1n-7,

Table 1. Fatty Acid Profiles of Hepatic Lipids

\begin{tabular}{|c|c|c|c|}
\hline \multirow{2}{*}{ Fatty acids } & Control & Fat-free diet & Clofibric acid \\
\hline & \multicolumn{3}{|c|}{$(\mathrm{mol} \%)$} \\
\hline $16: 0$ & $28.01 \pm 3.66^{\mathrm{a}}$ & $39.49 \pm 2.24^{b}$ & $28.01 \pm 1.84^{\mathrm{a}}$ \\
\hline $16: 1 n-7$ & $1.84 \pm 0.62^{\mathrm{a}}$ & $12.28 \pm 0.82^{b}$ & $1.73 \pm 0.34^{\mathrm{a}}$ \\
\hline $18: 0$ & $16.13 \pm 2.16^{\mathrm{a}}$ & $9.98 \pm 1.61^{b}$ & $17.75 \pm 1.08^{\mathrm{a}}$ \\
\hline $18: 1 n-7$ & $4.01 \pm 0.70^{\mathrm{a}}$ & $5.38 \pm 0.94^{\mathrm{b}}$ & $2.14 \pm 0.19^{c}$ \\
\hline $18: 1 n-9$ & $10.35 \pm 1.76^{\mathrm{a}}$ & $21.35 \pm 3.75^{\mathrm{b}}$ & $16.41 \pm 1.30^{\mathrm{c}}$ \\
\hline $18: 2 n-6$ & $21.48 \pm 1.31^{\mathrm{a}}$ & $2.41 \pm 0.56^{\mathrm{b}}$ & $10.04 \pm 0.54^{\mathrm{c}}$ \\
\hline $18: 3 n-3$ & $0.40 \pm 0.05^{\mathrm{a}}$ & $0.00 \pm 0.00^{\mathrm{b}}$ & $0.07 \pm 0.05^{b}$ \\
\hline $20: 3 n-9$ & $0.10 \pm 0.01^{\mathrm{a}}$ & $1.20 \pm 0.25^{\mathrm{b}}$ & $1.28 \pm 0.08^{\mathrm{b}}$ \\
\hline $20: 3 n-6$ & $0.67 \pm 0.16^{\mathrm{a}}$ & $0.52 \pm 0.19^{\mathrm{a}}$ & $2.95 \pm 0.22^{b}$ \\
\hline $20: 4 n-6$ & $12.68 \pm 3.39^{\mathrm{a}}$ & $5.54 \pm 1.58^{\mathrm{b}}$ & $15.63 \pm 1.26^{\mathrm{a}}$ \\
\hline $20: 5 n-3$ & $0.68 \pm 0.09^{\mathrm{a}}$ & $0.11 \pm 0.06^{\mathrm{b}}$ & $0.75 \pm 0.20^{\mathrm{a}}$ \\
\hline $22: 5 n-3$ & $0.99 \pm 0.24^{\mathrm{a}}$ & $0.00 \pm 0.00^{b}$ & $0.50 \pm 0.08^{\mathrm{c}}$ \\
\hline $22: 6 n-3$ & $2.66 \pm 0.48^{\mathrm{a}}$ & $1.74 \pm 0.49^{\mathrm{b}}$ & $2.74 \pm 0.36^{\mathrm{a}}$ \\
\hline Total ( $\mu \mathrm{mol} / \mathrm{g}$ liver $)$ & $125.4 \pm 15.5^{\mathrm{a}}$ & $175.3 \pm 11.9^{\mathrm{b}}$ & $115.4 \pm 8.9^{\mathrm{a}}$ \\
\hline Total ( $\mu \mathrm{mol} /$ liver $)$ & $1495 \pm 188^{\mathrm{a}}$ & $2320 \pm 331^{b}$ & $2216 \pm 117^{b}$ \\
\hline
\end{tabular}

Fatty acids are designated by the numbers of carbon atoms and double bonds; palmitic acid, 16:0; palmitoleic acid, 16:1n-7; stearic acid, 18:0; oleic acid, 18:1n-9; cisvaccenic acid, 18:1n-7; linoleic acid, 18:2n-6; $\alpha$-linolenic acid, 18:3n-3; 5,8,11-eicosatrienoic acid, 20:3n-9; 8,11,14-eicosatrienoic acid, 20:3n-6; arachidonic acid, 20:4n-6; 5,8,11,14,17-eicosapentaenoic acid, 20:5n-3; 7,10,13,16,19-docosapentaenoic acid, 22:5n-3; 4,7,10,13,16,19-docosahexaenoic acid, 22:6n-3. Rats were fed a standard diet for $28 \mathrm{~d}$, a fat-free diet for $28 \mathrm{~d}$, or a diet admixed with clofibric acid at $0.5 \%(w / w)$ for $7 \mathrm{~d}$. Values represent the mean \pm S.D. ( $n=5$ ). Means in the same row without a common superscript $(\mathrm{a}, \mathrm{b}, \mathrm{c})$ are significantly different $(p<0.05)$. 
18:1n-7, and 18:1n-9 within MUFAs in the livers of clofibric acid-treated rats were 9.5, 11.9, and 78.6\%, respectively (Fig. 2A).

Preferential Oxidation of $16: 1 n-9$ to $18: 1 n-7$ or $18: 1 n-9$ in the Liver Fatty acid oxidation rates were compared among $16: 1 n-7,18: 1 n-7$, and 18:1n-9 in vitro using liver homogenates (Tables 2, 3). The rates of mitochondrial oxidation

\section{A}
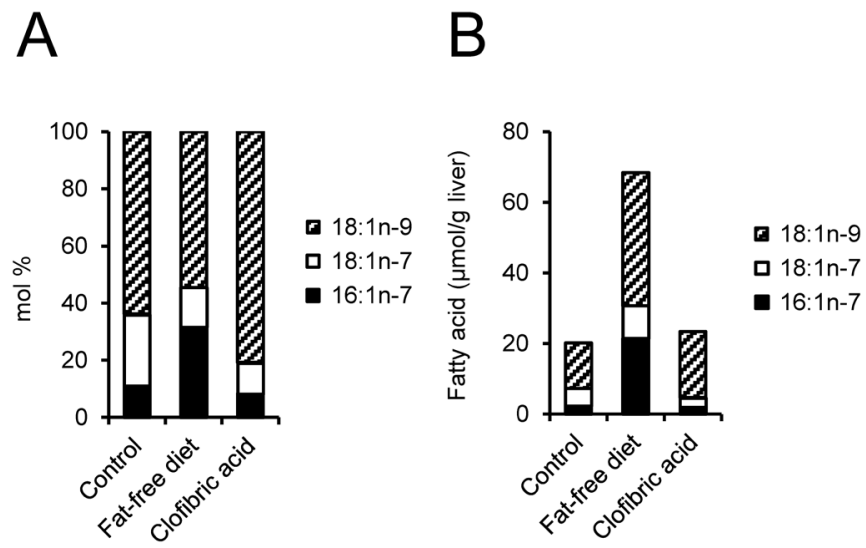

Fig. 2. Changes in Proportions within MUFAs and Contents of 16:1n-7, 18:1n-7, and 18:1n-9 in Hepatic Lipids by Fat-Free Diet Feeding and the Clofibric Acid Treatment

Rats were fed a standard diet for $28 \mathrm{~d}$, a fat-free diet for $28 \mathrm{~d}$, or a diet admixed with clofibric acid at $0.5 \%(\mathrm{w} / \mathrm{w})$ for $7 \mathrm{~d}$ before being killed. (A) Proportions $(\mathrm{mol} \%)$ within MUFAs (proportions of 16:1n-7, 18:1n-7, and 18:1n-9 in the sum of these three fatty acids); cumulative chart bars were calculated on the basis of data in Table 1. (B) Contents ( $\mu \mathrm{mol} / \mathrm{g}$ liver) of $16: 1 \mathrm{n}-7,18: 1 \mathrm{n}-7$, and $18: 1 \mathrm{n}-9$; cumulative chart bars were calculated on the basis of data in Table 1 . in vitro for the three MUFAs in control rats were in the following order: $16: 1 \mathrm{n}-7>18: 1 \mathrm{n}-7 \doteqdot 18: 1 \mathrm{n}-9$ (Table 2 ); the relative rates of oxidation for $16: 1 \mathrm{n}-7,18: 1 \mathrm{n}-7$, and $18: 1 \mathrm{n}-9$ were 1 , 0.45 , and 0.62 , respectively. The clofibric acid treatment markedly increased the mitochondrial oxidation of $16: 1 \mathrm{n}-7$, whereas fat-free diet feeding did not have a significant influence. The clofibric acid treatment also elevated the mitochondrial oxidation of $18: 1 n-7$ and $18: 1 n-9$ to largely the same extent as that observed with $16: 1 \mathrm{n}-7$, whereas fat-free diet feeding did not significantly change the oxidation rate of either $18: 1 n-7$ or $18: 1 n-9$. The relative rates of mitochondrial oxidation for $16: 1 n-7,18: 1 n-7$, and $18: 1 n-9$ in the homogenates of fat-free diet-fed and clofibric acid-treated rats were largely the same as those of control rats. The treatment of rats with clofibric acid markedly increased the levels of mRNA and protein for CPT1a (Figs. 3A, B); this pharmacological manipulation also up-regulated the expression of genes encoding medium-chain acyl-CoA dehydrogenase (MCAD), long-chain acyl-CoA dehydrogenase (LCAD), very long-chain acyl-CoA dehydrogenase (VLCAD), lipin 1, and peroxisome proliferator-activated receptor gamma coactivator $1 \alpha(\mathrm{PGCl} \alpha)$ (Fig. 3A). Fat-free diet feeding did not change the protein levels of CPT1a (Fig. 3B), despite the mRNA level of CPTla being increased (Fig. 3A); this dietary manipulation did not change the expression of genes encoding other enzymes related to mitochondrial oxidation (Fig. 3A). Regarding peroxisomal $\beta$-oxidation, the clofibric acid treatment markedly up-regulated the mRNA level of peroxisomal acyl-CoA oxidase 1 (ACOX1), whereas fat-free diet feeding did not (Supplementary Fig. 1). Since limited

Table 2. $\quad$ Mitochondrial $\beta$-Oxidation in Vitro of MUFAs in Liver Homogenates

\begin{tabular}{|c|c|c|c|}
\hline \multirow{2}{*}{ Fatty acids } & Control & Fat-free diet & Clofibric acid \\
\hline & \multicolumn{3}{|c|}{ (nmol/min/g liver) } \\
\hline \multirow[t]{2}{*}{$16: 1 n-7$} & $301 \pm 62^{\text {ax }}$ & $249 \pm 37^{\mathrm{ax}}$ & $831 \pm 36^{b x}$ \\
\hline & $(100.0 \pm 20.6)$ & $(82.7 \pm 12.3)$ & $(276.1 \pm 12.0)$ \\
\hline \multirow[t]{2}{*}{$18: 1 \mathrm{n}-7$} & $135 \pm 29^{\text {ay }}$ & $132 \pm 24^{\text {ay }}$ & $348 \pm 58^{\text {by }}$ \\
\hline & $(100.0 \pm 21.5)$ & $(97.8 \pm 17.8)$ & $(257.8 \pm 43.0)$ \\
\hline \multirow[t]{2}{*}{$18: 1 n-9$} & $187 \pm 35^{\text {ay }}$ & $164 \pm 12^{\mathrm{ay}}$ & $439 \pm 8^{\mathrm{bz}}$ \\
\hline & $(100.0 \pm 18.7)$ & $(87.7 \pm 6.4)$ & $(234.8 \pm 4.3)$ \\
\hline
\end{tabular}

Rats were fed a standard diet for $28 \mathrm{~d}$, a fat-free diet for $28 \mathrm{~d}$, or a diet admixed with clofibric acid at $0.5 \%$ (w/w) for $7 \mathrm{~d}$. The mitochondrial oxidation of $16: 1 \mathrm{n}-7$, $18: 1 \mathrm{n}-7$, and $18: 1 \mathrm{n}-9$ in liver homogenates was estimated in vitro. Liver homogenates were incubated with $\left[{ }^{14} \mathrm{C}\right] 16: 1 \mathrm{n}-7$, $\left[{ }^{14} \mathrm{C}\right] 18: 1 \mathrm{n}-7$, or $\left[{ }^{14} \mathrm{C}\right] 18: 1 \mathrm{n}-9$ in the presence and absence of $\mathrm{KCN} ;\left[{ }^{14} \mathrm{C}\right]$-labeled acid-soluble products were extracted and the ${ }^{14} \mathrm{CO}_{2}$ produced was trapped; the cyanide-sensitive part of oxidation was taken as mitochondrial oxidation. The rate of fatty acid oxidation is presented as the sum of acid-soluble oxidation products and $\mathrm{CO}_{2}$. Values in parentheses represent a percentage of the control. Values represent the mean \pm S.D. $(n=4)$. Means in the same row without a common superscript $(\mathrm{a}, \mathrm{b})$ are significantly different $(p<0.05)$. Means in the same column without a common superscript $(\mathrm{x}, \mathrm{y}, \mathrm{z})$ are significantly different $(p<0.05)$.

Table 3. Peroxisomal $\beta$-Oxidation in Vitro of MUFAs in Liver Homogenates

\begin{tabular}{|c|c|c|c|}
\hline \multirow{2}{*}{ Fatty acids } & Control & Fat-free diet & Clofibric acid \\
\hline & \multicolumn{3}{|c|}{ (nmol/min/mg protein) } \\
\hline \multirow[t]{2}{*}{$16: 1 n-7$} & $5.89 \pm 0.46^{\mathrm{ax}}$ & $4.25 \pm 0.52^{\mathrm{ax}}$ & $96.63 \pm 8.66^{\mathrm{bx}}$ \\
\hline & $(100.0 \pm 7.8)$ & $(72.2 \pm 8.8)$ & $(1640.6 \pm 147.0)$ \\
\hline \multirow[t]{2}{*}{$18: 1 n-7$} & $3.86 \pm 0.37^{\text {ay }}$ & $2.55 \pm 0.04^{\text {by }}$ & $54.91 \pm 0.83^{\text {cy }}$ \\
\hline & $(100.0 \pm 9.6)$ & $(66.1 \pm 1.0)$ & $(1422.5 \pm 21.5)$ \\
\hline \multirow[t]{2}{*}{$18: \ln -9$} & $3.75 \pm 0.10^{\text {ay }}$ & $2.61 \pm 0.01^{\mathrm{ay}}$ & $55.41 \pm 1.51^{\text {by }}$ \\
\hline & $(100.0 \pm 2.7)$ & $(69.4 \pm 0.3)$ & $(1477.6 \pm 40.3)$ \\
\hline
\end{tabular}

Rats were fed a standard diet for $28 \mathrm{~d}$, a fat-free diet for $28 \mathrm{~d}$, or a diet admixed with clofibric acid at $0.5 \%$ (w/w) for $7 \mathrm{~d}$. The peroxisomal oxidation of cis-palmitoleoyl$\mathrm{CoA}$, cis-vaccenoyl-CoA, and oleoyl-CoA in liver homogenates was estimated in vitro as the NAD ${ }^{+}$reduction rate. Values in parentheses represent a percentage of the control. Values represent the mean \pm S.D. $(n=4)$. Means in the same row without a common superscript $(\mathrm{a}, \mathrm{b}, \mathrm{c})$ are significantly different $(p<0.05)$. Means in the same column without a common superscript $(\mathrm{x}, \mathrm{y})$ are significantly different $(p<0.05)$. 
A

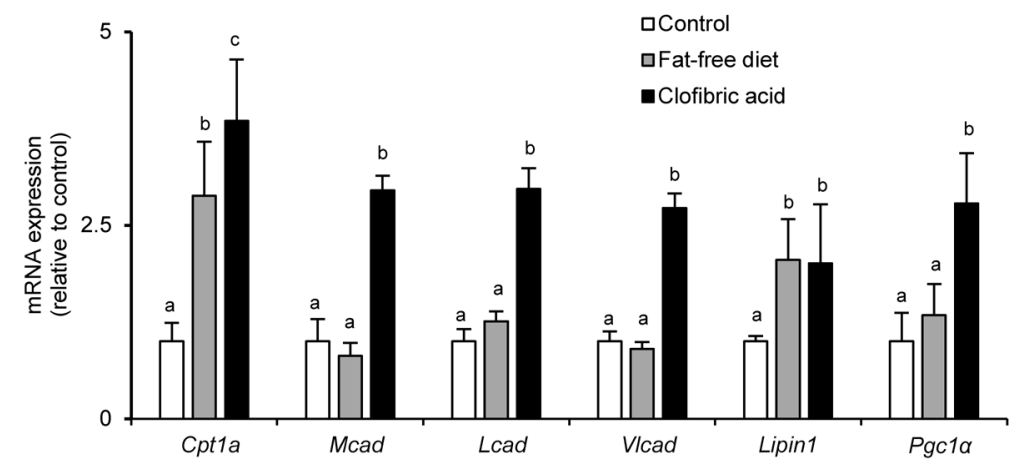

$\mathrm{B}$

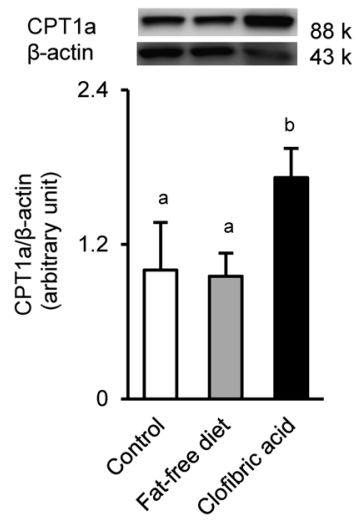

Fig. 3. Expression of Genes Encoding Enzymes Related to Mitochondrial $\beta$-Oxidation and of the CPT1a Protein

Rats were fed a standard diet for $28 \mathrm{~d}$, a fat-free diet for $28 \mathrm{~d}$, or a diet admixed with clofibric acid at $0.5 \%$ (w/w) for $7 \mathrm{~d}$. (A) mRNA encoding CPT1a, MCAD, LCAD, VLCAD, lipin1, and PGCl $\alpha$. (B) CPTla protein; visible bands represent CPTla and $\beta$-actin as indicated. Immunoblotting was carried out on liver extracts $(15 \mu \mathrm{g}$ of protein each). Values represent the mean \pm S.D. $(n=6-10) .{ }^{\mathrm{a}, \mathrm{b}, \mathrm{c}}$ Means without a common superscript are significantly different $(p<0.05)$. In the absence of a superscript, the means are not significantly different $(p>0.05)$.

Table 4. Oxidation Ex Vivo of MUFAs in Liver Slices

\begin{tabular}{cccc}
\hline \hline \multirow{2}{*}{ Fatty acids } & Control & Fat-free diet & Clofibric acid \\
\cline { 2 - 4 } & & $\left(\times 10^{5}\right.$ dpm/30 min/g liver $)$ & \\
\hline \multirow{2}{*}{$16: 1 \mathrm{n}-7$} & $1.63 \pm 0.20^{\text {ax }}$ & $0.48 \pm 0.12^{\text {bx }}$ & $2.18 \pm 0.33^{\text {cx }}$ \\
& $(100.0 \pm 12.3)$ & $(29.4 \pm 7.4)$ & $(133.8 \pm 20.2)$ \\
$18: 1 \mathrm{n}-7$ & $0.75 \pm 0.10^{\text {ay }}$ & $0.28 \pm 0.04^{\text {by }}$ & $1.28 \pm 0.19^{\text {cy }}$ \\
& $(100.0 \pm 13.3)$ & $(37.3 \pm 5.3)$ & $(170.7 \pm 25.3)$ \\
$18: 1 \mathrm{ln}-9$ & $0.81 \pm 0.17^{\text {ay }}$ & $0.17 \pm 0.07^{\text {by }}$ & $1.01 \pm 0.02^{\text {ay }}$ \\
& $(100.0 \pm 21.0)$ & $(21.0 \pm 8.6)$ & $(124.7 \pm 2.5)$ \\
\hline
\end{tabular}

Rats were fed a standard diet for $28 \mathrm{~d}$, a fat-free diet for $28 \mathrm{~d}$, or a diet admixed with clofibric acid at $0.5 \%$ (w/w) for $7 \mathrm{~d}$. Liver slices were incubated with $\left.{ }^{14} \mathrm{C}\right] 16: 1 \mathrm{n}-7$, $\left[{ }^{14} \mathrm{C}\right] 18: 1 \mathrm{n}-7$, or $\left[{ }^{14} \mathrm{C}\right] 18: 1 \mathrm{n}-9$. $\left[{ }^{14} \mathrm{C}\right]$-Labeled acid-soluble products were extracted and the ${ }^{14} \mathrm{CO}_{2}$ produced was trapped. The rate of fatty acid oxidation is presented as the sum of acid-soluble oxidation products and $\mathrm{CO}_{2}$. Values in parentheses represent a percentage of the control. Values represent the mean \pm S.D. ( $n=4-6$ ). Means in the same row without a common superscript $(\mathrm{a}, \mathrm{b}, \mathrm{c})$ are significantly different $(p<0.05)$. Means in the same column without a common superscript $(\mathrm{x}, \mathrm{y})$ are significantly different $(p<0.05)$.

information is available on the substrate specificity of peroxisomal $\beta$-oxidation for cis-palmitoleoyl-CoA, cis-vaccenoyl$\mathrm{CoA}$, and oleoyl-CoA, peroxisomal $\beta$-oxidation rates for the three types of acyl-CoA were compared (Table 3). In the livers of control rats, activities were in the following order: cispalmitoleoyl-CoA $>$ > cis-vaccenoyl-CoA=oleoyl-CoA; relative activities for cis-palmitoleoyl-CoA, cis-vaccenoyl-CoA, and oleoyl-CoA were $1,0.66$, and 0.64 , respectively. Relative activities in the livers of fat-free diet-fed and clofibric acid-treated rats were almost the same as those in the livers of control rats, although activities per se were markedly higher in clofibric acid-treated rats than in control rats. These results, which were obtained from an in vitro study, evidently indicate that $16: 1 n-7$ is degraded markedly faster than $18: 1 n-7$ or $18: 1 n-9$.

In order to confirm the results obtained from the in vitro study utilizing liver homogenates, an ex vivo experiment using liver slices was performed (Table 4). The rates of oxidation for the three MUFAs in the livers of control rats were in the following order: $16: 1 \mathrm{n}-7>18: 1 \mathrm{n}-7 \doteqdot 18: 1 \mathrm{n}-9$; the relative rates for $16: 1 \mathrm{n}-7,18: 1 \mathrm{n}-7$, and $18: 1 \mathrm{n}-9$ were $1,0.46$, and 0.50 , respectively. These rates were very similar to the results obtained in vitro from the liver homogenates of control rats. The rates of 16:1n-7 oxidation ex vivo in the liver slices of fat-free diet-fed and clofibric acid-treated rats were both approximately twofold greater than those of 18:1n-7 and 18:1n-9, similar to those in control rats. Upon feeding a fat-free diet, the oxidation rates of $16: 1 n-7,18: 1 n-7$, and $18: 1 n-9$ in liver slices were significantly lower than those in control rats. On the other hand, the oxidation rates of $16: 1 \mathrm{n}-7$ and $18: 1 \mathrm{n}-7$ in liver slices were significantly enhanced by the treatment of rats with clofibric acid. As a result, the rates of oxidation of 16:1n-7, 18:1n-7, and 18:1n-9 in liver slices were 4.54-, 4.57-, and 5.94-fold greater, respectively, in clofibric acid-treated rats than in fat-free dietfed rats.

Other Factors Potentially Affecting the Selective Oxidation of MUFAs The distribution of the three MUFAs among the lipid classes in the liver was investigated (Supplementary Table 2 and Fig. 4). In the livers of control rats, most of $16: 1 \mathrm{n}-7$ was distributed in TAG $(64.3 \%, 0.98 \mu \mathrm{mol} / \mathrm{g}$ liver) and phospholipids $(28.2 \%, 0.43 \mu \mathrm{mol} / \mathrm{g}$ liver); similarly, $18: 1 \mathrm{n}-9$ was mainly localized in TAG $(70.9 \%, 7.44 \mu \mathrm{mol} / \mathrm{g}$ liver) and phospholipids $(23.0 \%, 2.42 \mu \mathrm{mol} / \mathrm{g}$ liver). In contrast to $16: 1 \mathrm{n}-7$ and $18: 1 n-9,18: 1 n-7$ was predominantly distributed in phospholipids $(66.0 \%, 2.95 \mu \mathrm{mol} / \mathrm{g}$ liver $)$ while a smaller portion resided in TAG $(30.5 \%, 1.36 \mu \mathrm{mol} / \mathrm{g}$ liver). Upon feeding rats a fat-free diet, the hepatic contents of the three MUFAs were markedly increased (Fig. 2B). 16:1n-7 was predominantly present in TAG $(78.2 \%, 14.23 \mu \mathrm{mol} / \mathrm{g}$ liver) and phospholipids $(16.4 \%, 2.99 \mu \mathrm{mol} / \mathrm{g}$ liver), and similarly, 18:1n-9 mainly resided in TAG $(80.7 \%, 27.64 \mu \mathrm{mol} / \mathrm{g}$ liver) and phospholipids 
$\mathrm{B}$
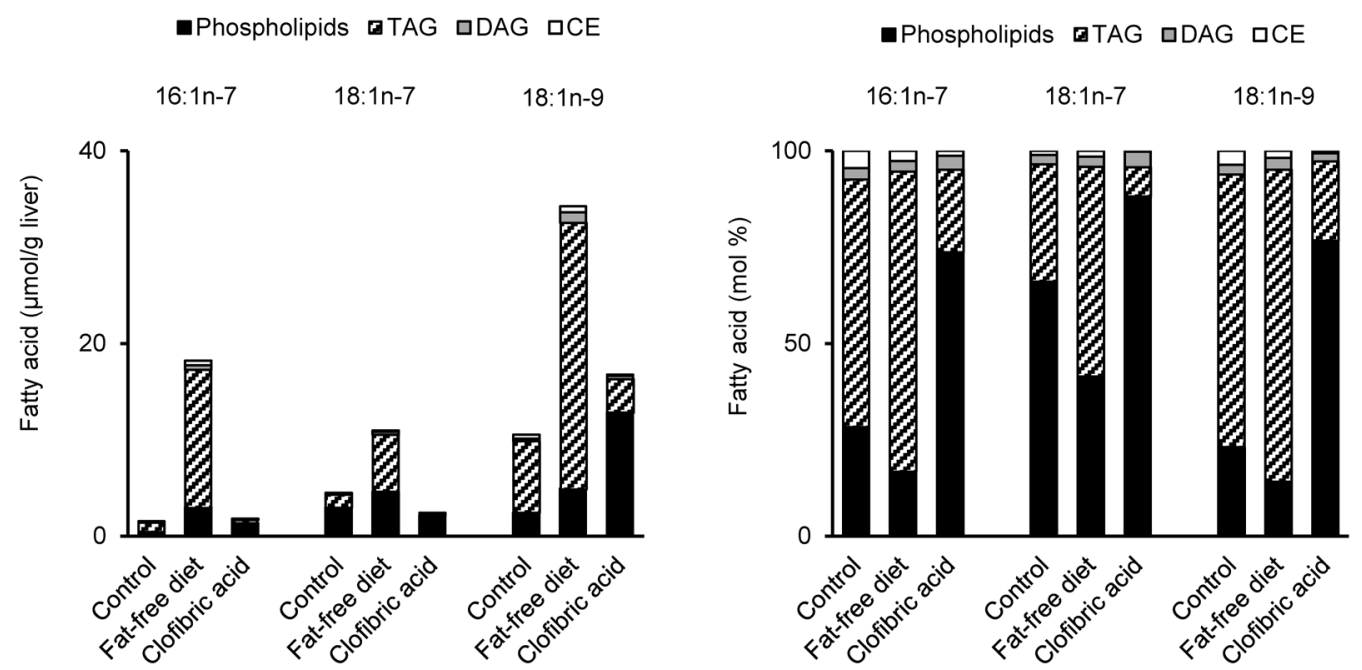

Fig. 4. Distribution of 16:1n-7, 18:1n-7, and 18:1n-9 among Phospholipids, TAG, DAG, and CE in the Liver

Rats were fed a standard diet for $28 \mathrm{~d}$, a fat-free diet for $28 \mathrm{~d}$, or a diet admixed with clofibric acid at $0.5 \%(\mathrm{w} / \mathrm{w})$ for $7 \mathrm{~d}$. (A) Contents of the three MUFAs in phospholipids, TAG, DAG, and CE. (B) Proportions (mol\%) among phospholipids, TAG, DAG, and CE. Cumulative bar charts were calculated on the basis of data in Supplementary Table 2 .

A

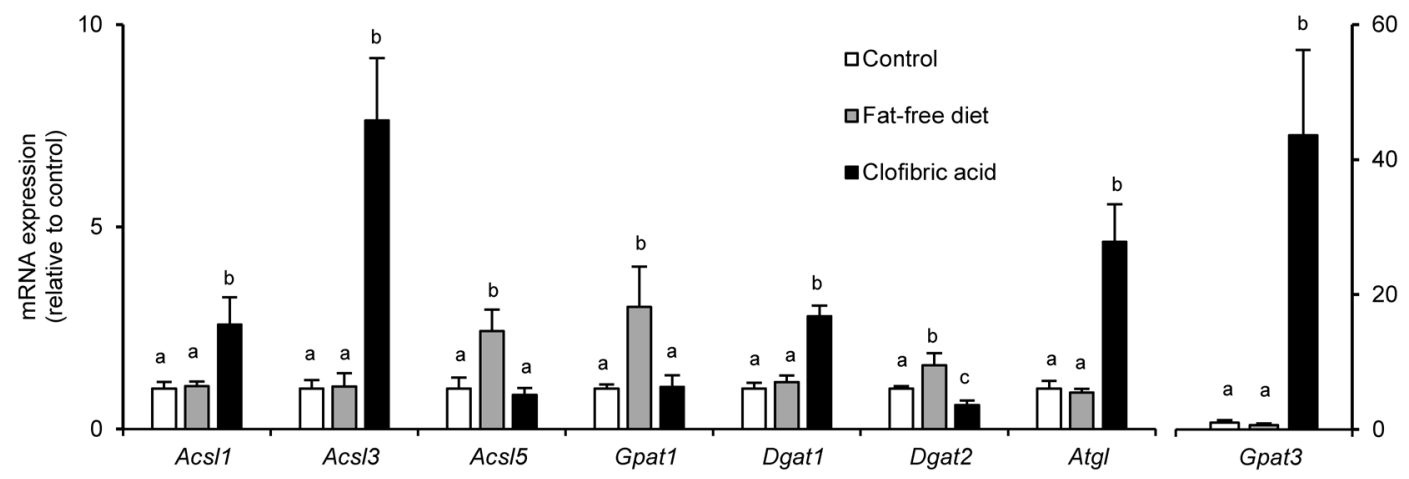

B
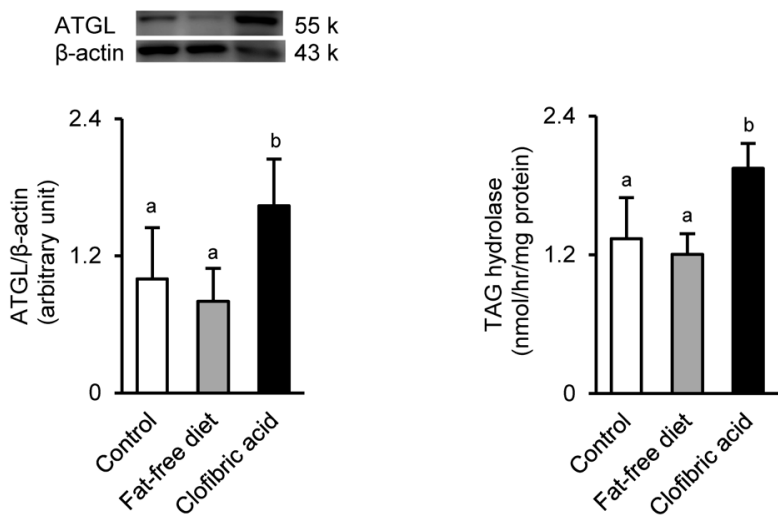

Fig. 5. Expression of Genes Encoding Enzymes Related to the Channeling of Fatty Acids towards Glycerolipid Synthesis Pathways and That of ATGL in the Liver

Rats were fed a standard diet for $28 \mathrm{~d}$, a fat-free diet for $28 \mathrm{~d}$, or a diet admixed with clofibric acid at $0.5 \%$ (w/w) for $7 \mathrm{~d}$. (A) mRNA encoding of ACSL1, ACSL3, ACSL5, GPAT1, GPAT3, DGAT1, DGAT2, and ATGL. (B) ATGL protein; visible bands represent ATGL and $\beta$-actin as indicated. Immunoblotting was carried out on liver extracts $\left(15 \mu \mathrm{g}\right.$ of protein each). (C) ATGL activities were estimated as $\left[{ }^{14} \mathrm{C}\right]$ triolein hydrolysis in the cytoplasmic fraction of the liver. Values represent the mean \pm S.D. $(n=5-6) .{ }^{\mathrm{a}, \mathrm{b}}$ Means without a common superscript are significantly different $(p<0.05)$. 
$(14.3 \%, 4.89 \mu \mathrm{mol} / \mathrm{g}$ liver) in the livers of fat-free diet-fed rats (Supplementary Table 2, Fig. 4). The treatment of rats with clofibric acid markedly increased the hepatic content of $18: 1 n-9$, whereas the contents of $16: 1 n-7$ and $18: 1 n-7$ in the livers of clofibric acid-treated rats were markedly less than that of 18:1n-9 (Fig. 2B). The clofibric acid treatment markedly increased the abundance of 18:1n-9 distributed in phospholipids (76.7\%, $12.84 \mu \mathrm{mol} / \mathrm{g}$ liver), whereas that of $18: 1 \mathrm{n}-9$ residing in TAG was reduced $(20.5 \%, 3.43 \mu \mathrm{mol} / \mathrm{g}$ liver) (Supplementary Table 2, Fig. 4).

It may be important to investigate whether a difference exists in the channeling of fatty acids toward the pathways of glycerolipid synthesis among the three experimental groups of animals because this process is considered to be associated with fatty acid degradation. ${ }^{41-45)}$ Among the enzymes that participate in the channeling of fatty acids in the liver, fat-free diet feeding increased the mRNA levels of long-chain acylCoA synthetase (ACSL) 5, glycerol-3-phosphate acyltransferase (GPAT) 1, and diglyceride acyltransferase (DGAT) 2; the clofibric acid treatment up-regulated the expression of genes for ACSL1, ACSL3, GPAT3, and DGAT1 (Fig. 5A). As for ATGL, the treatment with clofibric acid significantly elevated its mRNA (4.63-fold), protein (1.64-fold), and activity (1.45fold) levels in the liver, whereas the fat-free diet did not (Figs. $5 \mathrm{~A}-\mathrm{C})$.

\section{DISCUSSION}

Fatty acid modifications, in particular desaturation, are generally considered to play a predominant role in the regulation of the MUFA profile in the liver. ${ }^{16)}$ Early studies utilizing whole microsomes or purified SCD from rat livers showed that SCD exhibited specificity for palmitoyl-CoA ranging between 46 and $86 \%$ that for stearoyl-CoA. ${ }^{18-20)}$ Nevertheless, the proportion of $16: 1 n-7$ in the liver is markedly lower than that of 18:1n-9. To the best of our knowledge, no convincing explanation has yet been provided for the low level of 16:1n-7 in the liver. These findings led us to hypothesize that fatty acid $\beta$-oxidation, in addition to fatty acid modifications (desaturation and elongation), plays a key role in regulating the MUFA profile, particularly the proportion of $16: 1 \mathrm{n}-7$, in the liver. The present study demonstrated that the rate of $16: 1 \mathrm{n}-7$ oxidation in the liver was markedly greater than those of 18:1n-9 and $18: \ln -7$, which was attributed not only to mitochondrial $\beta$-oxidation, but also peroxisomal $\beta$-oxidation degrading $16: 1 n-7$ significantly faster than $18: 1 n-9$ or $18: 1 n-7$. These results strongly suggest that fatty acid oxidation maintains low hepatic levels of 16:1n-7 (Fig. 6A).

In an attempt to obtain a clearer understanding of the direct link between fatty acid $\beta$-oxidation and the proportion of $16: 1 \mathrm{n}-7$, the experimental approach that we applied was based on the use of two different types of manipulations of animals: fat-free diet feeding and a clofibric acid treatment. SCD, PCE, and POCE were markedly induced in the liver by these nutritional and pharmacological manipulations, and the increases observed in the activities of these enzymes in fat-free diet-fed rats were similar to those in clofibric acidtreated rats. Therefore, this study design made it possible to investigate the role of fatty acid $\beta$-oxidation in the regulation of the MUFA profile by eliminating the influence of desaturation and elongation. Ingested fatty acids may affect the fatty
A

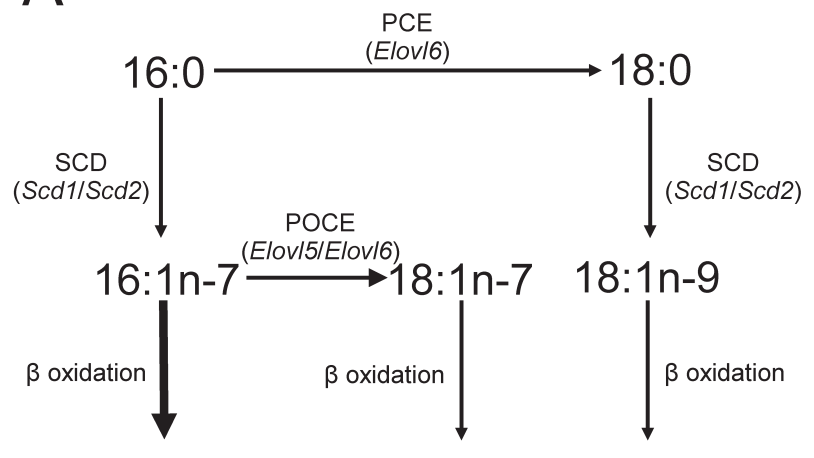

Degraded product

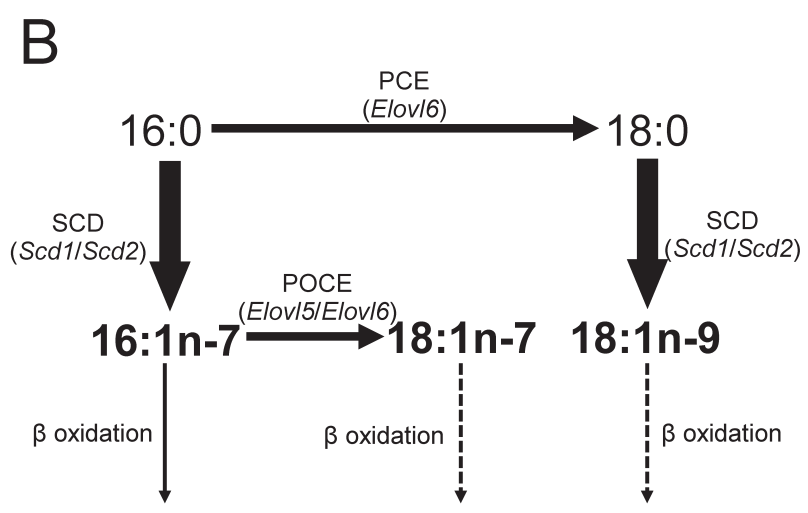

Degraded product

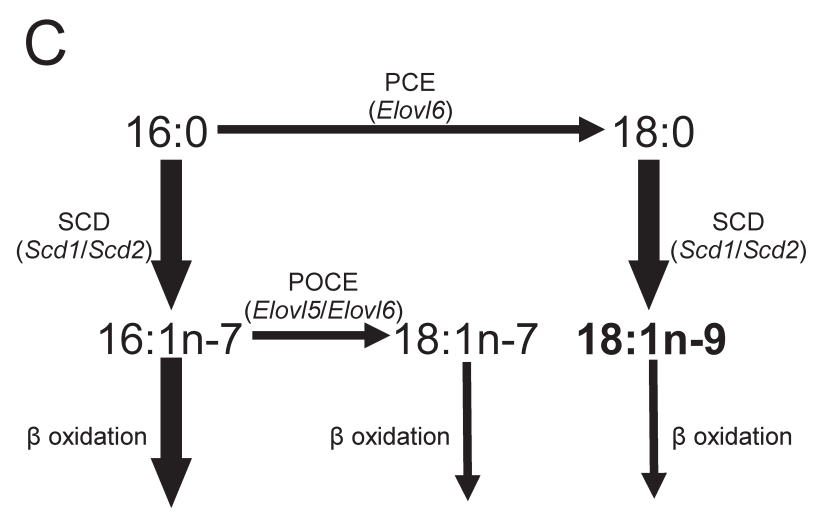

\section{Degraded product}

Fig. 6. Proposed Model for the Metabolic Regulation of the MUFA Profile in the Liver

(A) In the livers of control rats, the proportion of 16:1n-7 was maintained at low levels due to 1) the higher rate of oxidation of $16: 1 \mathrm{n}-7$ than those of $18: 1 \mathrm{n}-9$ and $18: 1 \mathrm{n}-7$ and 2) the conversion of $16: 1 \mathrm{n}-7$ to $18: 1 \mathrm{n}-7$ by elongation. (B) Upon the feeding of a fat-free diet to rats, the formation of $16: 1 \mathrm{n}-9,18: 1 \mathrm{n}-7$, and $18: 1 \mathrm{n}-9$ is increased by 1) up-regulated FAS, SCD, PCE, and POCE and 2) the unchanged or suppressed oxidation of 16:1n-9, 18:1n-7, and 18:1n-9. (C) The treatment of rats with clofibric acid increases the proportion and mass of $18: 1 n-9$ by up-regulated PCE and SCD; 16:1n-7 also appears to be generated by the induced SCD, whereas enhanced fatty acid oxidation degrades $16: 1 \mathrm{n}-7$ more extensively than $18: 1 \mathrm{n}-9$. The process of the incorporation of $16: 1 \mathrm{n}-7,18: 1 \mathrm{n}-7$, and 18:1n-9 into complex lipids, in particular TAG, may also influence the MUFA profile in the liver.

acid proportion in the liver because the completely balanced chow diet, on which control rats were fed, contained 18:1n-9 at a proportion of $19.7 \%$; on the other hand, the proportions of $16: 1 n-7$ and $18: 1 n-7$ in the chow diet were 2.0 and $2.2 \%$, 
respectively. Therefore, the higher proportion of 18:1n-9 in the livers of control rats may reflect the higher proportion of $18: 1 n-9$ in the diet. In order to exclude the influence of ingested MUFAs on the hepatic MUFA profile, the present study employed nutritional manipulation, namely, fat-free diet feeding. In the livers of these rats, essentially all saturated fatty acids and MUFAs are expected to be synthesized de novo from carbohydrates through the concerted actions of induced FAS, SCD, and elongases; moreover, fatty acid $\beta$-oxidation may not be enhanced. Upon feeding of the fat-free diet, the expression of genes responsible for enzymes related to the de novo synthesis of MUFAs (Fas, Accl, Mel, Acly, G6pd, Lpk, Scd1, Scd2, Elovl5, Elovl6, Acsl5) was markedly upregulated, whereas the activity of fatty acid $\beta$-oxidation was not. The up-regulation of ACSL5 may facilitate the formation of palmitoyl-CoA from 16:0, which is increasingly generated de novo by the FAS induced, and the palmitoyl-CoA produced is subsequently converted to $16: 1 n-7,18: 1 n-7$, and $18: 1 n-9$ by the SCD, PCE, and POCE induced by fat-free diet feeding. Consistent with the up-regulation of these fatty acid modification processes, the proportions and masses of 16:1n-7, 18:1n-7, and $18: 1 n-9$ were confirmed to be markedly increased in the liver. The accumulation of these three MUFAs in the liver may also be explained by the $\beta$-oxidation rates of MUFAs not being elevated in the liver homogenates, but being reduced in liver slices by fat-free diet feeding (Fig. 6B). Furthermore, the present study employed a clofibric acid treatment as another manipulation of animals. In contrast to the nutritional manipulation, not only SCD and elongases, but also fatty acid $\beta$-oxidation are expected to be up-regulated in the livers of clofibric acid-treated rats. ${ }^{34,36,37,46-48)}$ As expected, the activities of microsomal SCD, PCE, and POCE were markedly increased by the clofibric acid treatment, and the elevated levels observed were similar to those in fat-free diet-fed rats. Of particular importance in these results is that the proportions of 16:1n-7 and 18:1n-7 did not necessarily reflect the changes that occurred in the activities of SCD and/or POCE, despite the proportion of 18:1n-9 being markedly higher in the livers of clofibric acid-treated rats. Fatty acid oxidation rates in the liver were also significantly increased by the clofibric acid treatment with the enhanced expression of genes encoding enzymes related to fatty acid degradation (CPT1a, MCAD, LCAD, VLCAD, lipin 1, PGC1 $\alpha$, ACOX1, ACSL1). Consistent with the up-regulated expression of genes responsible for enzymes related to the rates of mitochondrial $\beta$-oxidation in vitro, the oxidation rates of MUFAs in the liver homogenates of clofibric acid-treated rats were markedly greater than those in control rats. Moreover, the rate of $16: 1 n-7$ oxidation was approximately two-fold greater than those of 18:1n-7 and 18:1n-9 in the liver homogenates of clofibric acid-treated rats. The rates of oxidation ex vivo of 16:1n-7, 18:1n-7, and 18:1n-9 in the liver slices of clofibric acid-treated rats were also confirmed to be elevated. ACSL1 is localized on both the endoplasmic reticulum and mitochondria, and partitions its product into synthetic and degradative pathways. ${ }^{49)}$ Since ACSL1 forms a complex with CPT1a and voltage-dependent anion channels on the outer mitochondrial membrane ${ }^{50)}$ and this complex may facilitate the transfer of acyl-CoA to CPTla, the increase observed in the expression of ACSL1 and CPT1a by the clofibric acid treatment may facilitate fatty acid degradation by mitochondrial $\beta$-oxidation (Fig. 6C).
Some of the isoforms of ACSL and GPAT are considered to channel fatty acids toward different metabolic pathways, such that changes in the expression of the isoforms of GPAT and ACSL may affect fatty acid degradation, ${ }^{41-43)}$ and a significant portion of fatty acids are initially channeled to TAG storage prior to hydrolysis by ATGL and are then degraded by $\beta$-oxidation. ${ }^{32,44,45)}$ These findings indicate that metabolic pathways other than fatty acid oxidation indirectly affect the differences noted in the degradation of MUFAs. The present study showed that the largest proportions of $16: 1 n-7$ and $18: 1 n-9$ resided in TAG in the livers of control rats and that fatty acid oxidation degraded 16:1n-7 markedly faster than $18: 1 n-9$ or $18: 1 n-7$. As a result, the proportion of $16: 1 n-7$ was significantly low in the livers of control rats (Fig. 6A). The present study also showed that fat-free diet feeding up-regulated the expression of Acsl5, Gpat1, and Dgat2 in the liver. Up-regulated ACSL5 and GPAT1 may reduce the degradation of MUFAs because these two enzymes reside on outer mitochondrial membranes, ${ }^{41,49,51,52)}$ channel increasingly generated MUFAs toward complex lipids (TAG, phospholipids, DAG, $\mathrm{CE}$ ), and divert them away from CPT1-mediated entry into mitochondria. ${ }^{43,52)}$ DGTA2 co-localizes with SCD1 on the endoplasmic reticulum, and is primarily responsible for incorporating endogenously synthesized MUFAs into TAG. ${ }^{53)}$ These findings are consistent with the present results showing that most of 16:1n-7 and 18:1n-9, and more than half of $18: 1 n-7$ resided in TAG in the livers of fat-free diet-fed rats. Collectively, these findings and results demonstrate that this nutritional manipulation markedly induced SCD to produce a large amount of $16: 1 n-7$, whereas some $16: 1 n-7$ was converted to $18: 1 n-7$ by up-regulated POCE; the remainder of $16: 1 n-7$ was incorporated into TAG in order to increase the proportions and contents of $16: 1 n-7$ in the liver because fatty acid oxidation was not elevated (Fig. 6B). In the livers of clofibric acidtreated rats, the formation of three MUFAs was increased. Most of 16:1n-7 and 18:1n-9 resided in phospholipids and the remainder in TAG; most of 18:1n-7 was in phospholipids. The treatment with clofibric acid up-regulated the expression of Acsl1, Acsl3, Gpat3, Dgat1, and Atgl. These results suggest that the clofibric acid treatment enhances the incorporation of fatty acids into not only phospholipids, but also TAG in hepatocytes. ${ }^{54-56)}$ Therefore, the synthesis of TAG rich in 16:1n-7 and 18:1n-9 may be enhanced in the livers of clofibric acidtreated rats. TAG are then degraded by the induced ATGL to produce unesterified $16: 1 \mathrm{n}-7$ and $18: 1 \mathrm{n}-9$, which are readily transferred to mitochondria in which they are converted to fatty acyl-CoAs by ACSL1 and are oxidized by the up-regulated mitochondrial $\beta$-oxidation system. Thus, not only differences in the efficiency of mitochondrial $\beta$-oxidation, but also in esterification into glycerolipids among 16:1n-7, 18:1n-7, and $18: 1 n-9$ appear to indirectly play some role in regulating the MUFA profile in the liver. Collectively, these results reinforce the concept that mitochondrial $\beta$-oxidation plays a key role in the regulation of the MUFA profile in the liver and, in particular, is crucially involved in maintaining low hepatic levels of 16:1n-7 (Fig. 6C).

Many lines of evidence from cellular and animal studies suggest that $16: 1 \mathrm{n}-7$ has biological functions that appear to be favorable for avoiding metabolic dysfunctions. ${ }^{6,7,9,57-60)} \mathrm{A}$ previous study demonstrated that circulating 16:1n-7 derived from adipose tissues strongly stimulated muscle insulin activ- 
ity and improved hepatic insulin activity in mice. ${ }^{7}$ Although some studies showed that higher blood levels of $16: 1 \mathrm{n}-7$ corresponded to insulin sensitivity, ${ }^{61)}$ other human subject studies described relationships between biological functions and circulating concentrations of $16: 1 n-7$ that negatively impacted on metabolic health. ${ }^{11,12,62-64)}$ Overall, the most persuasive explanation appears to be that although $16: 1 n-7$ has biological functions, not all of these features are necessarily beneficial for human health. Since a previous study suggested the autocrine and paracrine/endocrine characteristics of $\left.16: 1 \mathrm{n}-7,{ }^{65}\right)$ plasma $16: 1 \mathrm{n}-7$ and endogenously formed $16: 1 \mathrm{n}-7$ are both the most likely to contribute to its biological functions. Moreover, a recent study suggested that $18: 1 n-9$ endogenously produced in the liver suppressed de novo lipogenesis and fatty acid oxidation in white adipose tissues. ${ }^{15)}$ Thus, since it is conceivable that the liver widely distributes MUFAs to extra-hepatic tissues through the circulation, it is reasonable to speculate that the MUFA profile, particularly the proportion of $16: 1 n-7$, within the liver must be efficiently controlled. In this context, the present study showed that fatty acid oxidation, particularly mitochondrial $\beta$-oxidation, preferentially degraded $16: 1 \mathrm{n}-7$ and also that POCE elongated 16:1n-7 to synthesize $18: 1 \mathrm{n}-7$, which is pathophysiologically not as active and/or as detrimental as $16: 1 n-7$, such that the hepatic proportion and content of 16:1n-7 were maintained at low levels and the mass of 18:1n-7 was markedly less than that of $18: 1 n-9$ in the liver.

In conclusion, the present study provided evidence to support the potential of fatty acid oxidation, in concert with fatty acid modifications (desaturation, elongation), playing a key role in regulating the MUFA profile in the liver. Fatty acid oxidation is likely to be crucially involved in maintaining low 16:1n-7 levels in the liver.

Conflict of Interest The authors declare no conflict of interest.

Supplementary Materials The online version of this article contains supplementary materials.

\section{REFERENCES}

1) Ariyama $\mathrm{H}$, Kono $\mathrm{N}$, Matsuda $\mathrm{S}$, Inoue $\mathrm{T}$, Arai $\mathrm{H}$. Decrease in membrane phospholipid unsaturation induces unfolded protein response. J. Biol. Chem., 285, 22027-22035 (2010).

2) Shaw B, Lambert S, Wong MH, Ralston JC, Stryjecki C, Mutch DM. Individual saturated and monounsaturated fatty acids trigger distinct transcriptional networks in differentiated 3T3-L1 preadipocytes. J. Nutrigenet. Nutrigenomics, 6, 1-15 (2013).

3) Watt MJ, Hoy AJ, Muoio DM, Coleman RA. Distinct roles of specific fatty acids in cellular processes: implications for interpreting and reporting experiments. Am. J. Physiol. Endocrinol. Metab., 302, E1-E3 (2012)

4) Spector AA, Yorek MA. Membrane lipid composition and cellular function. J. Lipid Res., 26, 1015-1035 (1985).

5) Igal RA. Stearoyl-CoA desaturase-1: a novel key player in the mechanisms of cell proliferation, programmed cell death and transformation to cancer. Carcinogenesis, 31, 1509-1515 (2010).

6) $\mathrm{Wu}$ Y, Li R, Hildebrand DF. Biosynthesis and metabolic engineering of palmitoleate production, an important contributor to human health and sustainable industry. Prog. Lipid Res., 51, 340-349 (2012).

7) Cao H, Gerhold K, Mayers JR, Wiest MM, Watkins SM, Hota- misligil GS. Identification of a lipokine, a lipid hormone linking adipose tissue to systemic metabolism. Cell, 134, 933-944 (2008).

8) Burns TA, Kadegowda AK, Duckett SK, Pratt SL, Jenkins TC. Palmitoleic (16:1 cis-9) and cis-vaccenic (18:1 cis-11) acid alter lipogenesis in bovine adipocyte cultures. Lipids, 47, 1143-1153 (2012).

9) Bolsoni-Lopes A, Festuccia WT, Chimin P, Farias TS, Torres-Leal FL, Cruz MM, Andrade PB, Hirabara SM, Lima FB, Alonso-Vale MI. Palmitoleic acid (n-7) increases white adipocytes GLUT4 content and glucose uptake in association with AMPK activation. Lipids Health Dis., 13, 199 (2014).

10) Gong J, Campos H, McGarvey S, Wu Z, Goldberg R, Baylin A. Adipose tissue palmitoleic acid and obesity in humans: does it behave as a lipokine? Am. J. Clin. Nutr., 93, 186-191 (2011).

11) Mozaffarian D, Cao H, King IB, Lemaitre RN, Song $X$, Siscovick DS, Hotamisligil GS. Circulating palmitoleic acid and risk of metabolic abnormalities and new-onset diabetes. Am. J. Clin. Nutr., 92, 1350-1358 (2010).

12) Djoussé L, Matthan NR, Lichtenstein AH, Gaziano JM. Red blood cell membrane concentration of cis-palmitoleic and cis-vaccenic acids and risk of coronary heart disease. Am. J. Cardiol., 110, 539-544 (2012).

13) Block R, Kakinami L, Liebman S, Shearer GC, Kramer H, Tsai M. Cis-vaccenic acid and the Framingham risk score predict chronic kidney disease: the multi-ethnic study of atherosclerosis (MESA). Prostaglandins Leukot. Essent. Fatty Acids, 86, 175-182 (2012).

14) Tripathy S, Jump DB. Elovl5 regulates the mTORC2-Akt-FOXO1 pathway by controlling hepatic cis-vaccenic acid synthesis in dietinduced obese mice. J. Lipid Res., 54, 71-84 (2013).

15) Burhans MS, Flowers MT, Harrington KR, Bond LM, Guo CA, Anderson RM, Ntambi JM. Hepatic oleate regulates adipose tissue lipogenesis and fatty acid oxidation. J. Lipid Res., 56, 304-318 (2015).

16) Guillou H, Zadravec D, Martin PG, Jacobsson A. The key roles of elongases and desaturases in mammalian fatty acid metabolism: Insights from transgenic mice. Prog. Lipid Res., 49, 186-199 (2010).

17) Karahashi M, Ishii F, Yamazaki T, Imai K, Mitsumoto A, Kawashima Y, Kudo N. Up-regulation of stearoyl-CoA desaturase 1 increases liver MUFA content in obese Zucker but not Goto-Kakizaki rats. Lipids, 48, 457-467 (2013).

18) Lee CJ, Sprecher H. An in vitro study of the effects of dietary alteration and fasting on the desaturation of palmitic, stearic eicosa-8,11dienoic and eicosa-8,11,14-trienoic acids. Biochim. Biophys. Acta, 248, 180-185 (1971).

19) Jeffcoat R, Brawn PR, Safford R, James AT. Properties of rat liver microsomal stearoyl-coenzyme A desaturase. Biochem. J., 161, 431-437 (1977).

20) Enoch HG, Catala A, Strittmatter P. Mechanism of rat liver microsomal stearyl-CoA desaturase. Studies of the substrate specificity, enzyme-substrate interactions, and the function of lipid. J. Biol. Chem., 251, 5095-5103 (1976).

21) Tanaka S, Yagi Y, Yamazaki T, Mitsumoto A, Kobayashi D, Kudo N, Kawashima Y. Characterization of fatty acid profile in the liver of SHR/NDmcr-cp (cp/cp) rats, a model of the metabolic syndrome. Biol. Pharm. Bull., 35, 184-191 (2012).

22) Dannenberg AJ, Zakim D. Dietary lipid regulates the amount and functional state of UDP-glucuronosyltransferase in rat liver. $J$. Nutr., 122, 1607-1613 (1992).

23) Kudo N, Toyama T, Mitsumoto A, Kawashima Y. Regulation by carbohydrate and clofibric acid of palmitoyl-CoA chain elongation in the liver of rats. Lipids, 38, 531-537 (2003).

24) Nakagawa M, Uchiyama M. Esterification reaction affecting the pattern of mono-unsaturated fatty acids in rat liver. J. Biochem., 65 , 673-677 (1969).

25) Okuyama H, Inoue M. Preparation and analysis of radiolabeled phosphatidylcholine and phosphatidylethanolamine containing $3 \mathrm{H}-$ and 14C-labeled polyunsaturated fatty acids. Methods Enzymol., 86, 
370-376 (1982).

26) Valicenti AJ, Pusch FJ, Holman RT. Synthesis of octadecynoic acids and $\left[1-{ }^{14} \mathrm{C}\right]$ labeled isomers of octadecenoic acids. Lipids, 20, 234-242 (1985).

27) Lowry OH, Rosebrough NJ, Farr AL, Randall RJ. Protein measurement with the Folin phenol reagent. J. Biol. Chem., 193, 265-275 (1951).

28) Bligh EG, Dyer WJ. A rapid method of total lipid extraction and purification. Can. J. Biochem. Physiol., 37, 911-917 (1959).

29) Imai K, Koyama M, Kudo N, Shirahata A, Kawashima Y. Increase in hepatic content of oleic acid induced by dehydroepiandrosterone in the rat. Biochem. Pharmacol., 58, 925-933 (1999).

30) Yamazaki T, Kadokura M, Mutoh Y, Sakamoto T, Okazaki M, Mitsumoto A, Kawashima Y, Kudo N. Inducing effect of clofibric acid on stearoyl-CoA desaturase in intestinal mucosa of rats. Lipids, 49, 1203-1214 (2014).

31) Karahashi M, Hoshina M, Yamazaki T, Sakamoto T, Mitsumoto A, Kawashima Y, Kudo N. Fibrates reduce triacylglycerol content by upregulating adipose triglyceride lipase in the liver of rats. J. Pharmacol. Sci., 123, 356-370 (2013).

32) Reid BN, Ables GP, Otlivanchik OA, Schoiswohl G, Zechner R, Blaner WS, Goldberg IJ, Schwabe RF, Chua SC Jr, Huang LS. Hepatic overexpression of hormone-sensitive lipase and adipose triglyceride lipase promotes fatty acid oxidation, stimulates direct release of free fatty acids, and ameliorates steatosis. J. Biol. Chem., 283, 13087-13099 (2008).

33) Nepokroeff CM, Lakshmanan MR, Porter JW. Fatty-acid synthase from rat liver. Methods Enzymol., 35, 37-44 (1975).

34) Kawashima Y, Kozuka H. Regulation of palmitoyl-CoA chain elongation and linoleoyl-CoA chain elongation in rat liver microsomes and the differential effects of peroxisome proliferators, insulin and thyroid hormone. Biochim. Biophys. Acta, 834, 118-123 (1985).

35) Wu JW, Wang SP, Alvarez F, Casavant S, Gauthier N, Abed L, Soni KG, Yang G, Mitchell GA. Deficiency of liver adipose triglyceride lipase in mice causes progressive hepatic steatosis. Hepatology, 54, $122-132$ (2011)

36) Mannaerts GP, Debeer LJ, Thomas J, De Schepper PJ. Mitochondrial and peroxisomal fatty acid oxidation in liver homogenates and isolated hepatocytes from control and clofibrate-treated rats. J. Biol. Chem., 254, 4585-4595 (1979).

37) Lazarow PB, De Duve C. A fatty acyl-CoA oxidizing system in rat liver peroxisomes; enhancement by clofibrate, a hypolipidemic drug. Proc. Natl. Acad. Sci. U.S.A., 73, 2043-2046 (1976).

38) Krumdieck CL, dos Santos JE, Ho KJ. A new instrument for the rapid preparation of tissue slices. Anal. Biochem., 104, 118-123 (1980).

39) Friedman MI, Harris RB, Ji H, Ramirez I, Tordoff MG. Fatty acid oxidation affects food intake by altering hepatic energy status. Am. J. Physiol., 276, R1046-R1053 (1999).

40) Wang Y, Botolin D, Xu J, Christian B, Mitchell E, Jayaprakasam B, Nair MG, Peters JM, Busik JV, Olson LK, Jump DB. Regulation of hepatic fatty acid elongase and desaturase expression in diabetes and obesity. J. Lipid Res., 47, 2028-2041 (2006).

41) Grevengoed TJ, Klett EL, Coleman RA. Acyl-CoA metabolism and partitioning. Аnnu. Rev. Nutr., 34, 1-30 (2014).

42) Coleman RA, Mashek DG. Mammalian triacylglycerol metabolism: synthesis, lipolysis, and signaling. Chem. Rev., 111, 6359-6386 (2011)

43) Wendel AA, Cooper DE, Ilkayeva OR, Muoio DM, Coleman RA. Glycerol-3-phosphate acyltransferase (GPAT)-1, but not GPAT4, incorporates newly synthesized fatty acids into triacylglycerol and diminishes fatty acid oxidation. J. Biol. Chem., 288, 27299-27306 (2013).

44) Kanaley JA, Shadid S, Sheehan MT, Guo Z, Jensen MD. Relationship between plasma free fatty acid, intramyocellular triglycerides and long-chain acylcarnitines in resting humans. J. Physiol., 587,
5939-5950 (2009).

45) Lankester DL, Brown AM, Zammit VA. Use of cytosolic triacylglycerol hydrolysis products and of exogenous fatty acid for the synthesis of triacylglycerol secreted by cultured rat hepatocytes. $J$. Lipid Res., 39, 1889-1895 (1998)

46) Kawashima Y, Kozuka H. Increased activity of stearoyl-CoA desaturation in liver from rat fed clofibric acid. Biochim. Biophys. Acta, 713, 622-628 (1982).

47) Yamazaki T, Okada H, Sakamoto T, Sunaga K, Tsuda T, Mitsumoto A, Kudo N, Kawashima Y. Differential induction of stearoyl-CoA desaturase 1 and 2 genes by fibrates in the liver of rats. Biol. Pharm. Bull., 35, 116-120 (2012).

48) Lipsky NG, Pedersen PL. Perturbation by clofibrate of mitochondrial levels in animal cells. Implications for a model of mitochondrial genesis. J. Biol. Chem., 257, 1473-1481 (1982).

49) Li LO, Ellis JM, Paich HA, Wang S, Gong N, Altshuller G, Thresher RJ, Koves TR, Watkins SM, Muoio DM, Cline GW, Shulman GI, Coleman RA. Liver-specific loss of long chain acyl-CoA synthetase-1 decreases triacylglycerol synthesis and beta-oxidation and alters phospholipid fatty acid composition. J. Biol. Chem., 284, 27816-27826 (2009).

50) Lee K, Kerner J, Hoppel CL. Mitochondrial carnitine palmitoyltransferase 1a (CPT1a) is part of an outer membrane fatty acid transfer complex. J. Biol. Chem., 286, 25655-25662 (2011).

51) Pellon-Maison M, Montanaro MA, Coleman RA, Gonzalez-Baro MR. Mitochondrial glycerol-3-P acyltransferase 1 is most active in outer mitochondrial membrane but not in mitochondrial associated vesicles (MAV). Biochim. Biophys. Acta, 1771, 830-838 (2007).

52) Bu SY, Mashek DG. Hepatic long-chain acyl-CoA synthetase 5 mediates fatty acid channeling between anabolic and catabolic pathways. J. Lipid Res., 51, 3270-3280 (2010).

53) Man WC, Miyazaki M, Chu K, Ntambi J. Colocalization of SCD1 and DGAT2: implying preference for endogenous monounsaturated fatty acids in triglyceride synthesis. J. Lipid Res., 47, 1928-1939 (2006).

54) Poppelreuther M, Rudolph B, Du C, Grossmann R, Becker M, Thiele C, Ehehalt R, Fullekrug J. The N-terminal region of acylCoA synthetase 3 is essential for both the localization on lipid droplets and the function in fatty acid uptake. J. Lipid Res., 53, 888-900 (2012).

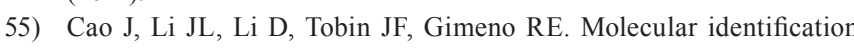
of microsomal acyl-CoA:glycerol-3-phosphate acyltransferase, a key enzyme in de novo triacylglycerol synthesis. Proc. Natl. Acad. Sci. U.S.A., 103, 19695-19700 (2006).

56) Qi J, Lang W, Geisler JG, Wang P, Petrounia I, Mai S, Smith C, Askari H, Struble GT, Williams R, Bhanot S, Monia BP, Bayoumy S, Grant E, Caldwell GW, Todd MJ, Liang Y, Gaul MD, Demarest KT, Connelly MA. The use of stable isotope-labeled glycerol and oleic acid to differentiate the hepatic functions of DGAT1 and $-2 . J$. Lipid Res., 53, 1106-1116 (2012).

57) Dimopoulos N, Watson M, Sakamoto K, Hundal HS. Differential effects of palmitate and palmitoleate on insulin action and glucose utilization in rat L6 skeletal muscle cells. Biochem. J., 399, 473-481 (2006).

58) Bolsoni-Lopes A, Festuccia WT, Farias TS, Chimin P, Torres-Leal FL, Derogis PB, de Andrade PB, Miyamoto S, Lima FB, Curi R, Alonso-Vale MI. Palmitoleic acid (n-7) increases white adipocyte lipolysis and lipase content in a PPARalpha-dependent manner. Am. J. Physiol. Endocrinol. Metab., 305, E1093-E1102 (2013)

59) Yang ZH, Miyahara H, Hatanaka A. Chronic administration of palmitoleic acid reduces insulin resistance and hepatic lipid accumulation in KK-Ay Mice with genetic type 2 diabetes. Lipids Health Dis., 10, 120 (2011).

60) Burns TA, Duckett SK, Pratt SL, Jenkins TC. Supplemental palmitoleic (C16:1 cis-9) acid reduces lipogenesis and desaturation in bovine adipocyte cultures. J. Anim. Sci., 90, 3433-3441 (2012). 
61) Stefan N, Kantartzis K, Celebi N, Staiger H, Machann J, Schick F, Cegan A, Elcnerova M, Schleicher E, Fritsche A, Haring HU. Circulating palmitoleate strongly and independently predicts insulin sensitivity in humans. Diabetes Care, 33, 405-407 (2010).

62) Fabbrini E, Magkos F, Su X, Abumrad NA, Nejedly N, Coughlin CC, Okunade AL, Patterson BW, Klein S. Insulin sensitivity is not associated with palmitoleate availability in obese humans. J. Lipid Res., 52, 808-812 (2011)

63) Djoussé L, Weir NL, Hanson NQ, Tsai MY, Gaziano JM. Plasma phospholipid concentration of cis-palmitoleic acid and risk of heart failure. Circ. Heart Fail., 5, 703-709 (2012).

64) Volk BM, Kunces LJ, Freidenreich DJ, Kupchak BR, Saenz C, Artistizabal JC, Fernandez ML, Bruno RS, Maresh CM, Kraemer WJ, Phinney SD, Volek JS. Effects of step-wise increases in dietary carbohydrate on circulating saturated fatty acids and palmitoleic acid in adults with metabolic syndrome. PLoS ONE, 9, el13605 (2014).

65) Koeberle A, Shindou H, Harayama T, Shimizu T. Palmitoleate is a mitogen, formed upon stimulation with growth factors, and converted to palmitoleoyl-phosphatidylinositol. J. Biol. Chem., 287, 27244-27254 (2012). 